FREDERICO AUGUSTO COSTA E LIMA SOARES

\title{
INFLUÊNCIA DA PRÁTICA VIRTUAL DE YOGA SOBRE O CONTROLE POSTURAL DE MULHERES IDOSAS UTILIZANDO O NINTENDO WII
}

Dissertação de mestrado apresentada ao Programa de Pós-Graduação Interunidades Bioengenharia - Escola de Engenharia de São Carlos / Faculdade de Medicina de Ribeirão Preto / Instituto de Química de São Carlos da Universidade de São Paulo como parte dos requisitos para a obtenção do título de mestre em Ciências.

Área de Concentração: Bioengenharia

Orientadora: Profa. Dra. Carla da Silva Santana

São Carlos

2011 
AUTORIZO A REPRODUÇÃO E DIVULGAÇÃO TOTAL OU PARCIAL DESTE TRABALHO, POR QUALQUER MEIO CONVENCIONAL OU ELETRÓNICO, PARA FINS DE ESTUDO E PESQUISA, DESDE QUE CITADA A FONTE.

Ficha catalográfica preparada pela Seção de Tratamento da Informação do Serviço de Biblioteca - EESC/USP

Soares, Frederico Augusto Costa e Lima

Influência da prática virtual de yoga sobre o controle postural de mulheres idosas utilizando o Nintendo Wii / Frederico Augusto Costa e Lima Soares; orientadora Carla da Silva Santana. -- São Carlos, 2011.

Dissertação (Mestrado-Programa de Pós-Graduação de Interunidades em Bioengenharia e Área de Concentração em Bioengenharia) -- Escola de Engenharia de são Carlos, Faculdade de Medicina de Ribeirão Preto; Instituto de Química de São Carlos da Universidade de são Paulo, 2011.

1. Idosos. 2. Controle postural. 3. Nintendo Wii. 4. Gerontologia. I. Título. 
FREDERICO AUGUSTO COSTA E LIMA SOARES

Título: "Influência da prática virtual de Yoga sobre o controle postural das mulheres idosas utilizando o Nintendo Wii" DISSERTAČ̃̃O APRESENTADA AO PROGRAMA DE PÓS -
GRADUAÇÂOO INTERUNIDADES BIOENGENHARIA EESC - FMRP - IQSC DA UNIVERSIDADE DE SÃO PAULO PARA OBTENÇÃO DO TÍTULO DE MESTRE EM CIÊNCIAS NA ÁREA DE BIOENGENHARIA.

Aprovado em: $24 / 10 / 2014$

PROFa. DR ${ }^{a}$. CARLA DA SILVA SANTANA (ORIENTADORA)

Resultado

apmoneror
Faculdade de Medicina de Ribeirão Preto USP

Assinatura:_ bltanfame

Faculdade de Medicina de Ribeirão Preto USP

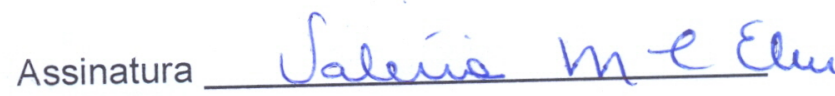

Universidade Estadual Paulista "Júlio de Mesquita Filho"

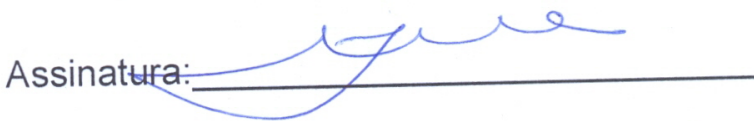

Resultado: aprorcedo 
Dedico este trabalho

principalmente a Deus e a minha família. 


\section{AGRADECIMENTOS}

Gostaria de agradecer primeiramente a Deus e meus espíritos protetores por sempre estarem presente me orientando a escolher sempre os melhores caminhos.

À Professora Dra. Carla da Silva Santana, pela orientação, apoio, ensinamentos, amizade, e principalmente pelo bom humor, perseverança e paciência de sempre, sempre. Mesmo quando as coisas não iam la muito bem.

Aos meus pais Yâne e José Carlos por terem me apoiado desde o começo, me dando condições e me compreendido nos momentos mais difíceis.

Ao meu filho José Eduardo que mesmo sem saber foi um dos grandes responsáveis pela força de ter seguido em frente até o final.

À minha namorada Gabriela, por ter tido compreensão e carinho dedicando seu tempo e seu coração sempre com o objetivo de me ajudar e me apoiar, e por ser essa pessoa maravilhosa que é.

À Profa. Dra. Vanessa Miranda.e aos amigos do IBRAM por terem me incentivado a iniciar esse novo trajeto em minha carreira profissional.

Ao meu querido tio Leonardo Lima, que me apoiou e me mostrou o caminho para que conseguisse alcançar essa nova etapa em minha vida.

À fisioterapeuta Ms. Patrícia Silva, grande responsável por termos conseguido levar a frente os principais objetivos do trabalho, pela total dedicação que apresentou aos desafios, minha eterna gratidão.

Ao Ms. Matheus Gomes, por todas as suas dicas e tempos gastos em orientações e aconselhamentos em seus horários de trabalho.

Aos queridos amigos de SENAC, Marta Fuzizawa Caparini, Edmara Salomão e Suzana Nambu por terem segurado as pontas quando tudo estava tão difícil, e por vezes tive que contar com a compreensão de vocês.

Aos membros da banca: Profa. Dra. Valéria Carriu Elui, Profa. Dra. Cristina Yoshie Toyoda, Prof. Dr. Lauro Wichert Ana e Prof. Dr. João Eduardo Araújo pelas valiosas contribuições.

Aos colegas do mestrado, principalmente Fausto, Dany, Samira, Maysa, Vinicius, Talita, Marina, Rafaela, Rodrigo, Taiú, Frank e outros tantos pela convivência diária, pela amizade, incentivo constante e pela torcida.

Aos grandes amigos da minha vida, que indiretamente participaram e torceram pelo meu sucesso e minha felicidade.

À todos os idosos que participaram parcial ou integralmente da pesquisa, pela confiança e contribuição.

Aos funcionários desta Instituição, em especial a Janete, Soninha, Nelson e a todos professores e funcionários da USP/SC, USP/RP, ECEU-centro e CIR-HE que de alguma forma contribuíram para a realização da pesquisa.

À todos a minha eterna gratidão, grande abraço. 


\section{RESUMO}

SOARES, F. A. C. L. Influência da prática virtual de Yoga sobre o controle postural de mulheres idosas utilizando o Nintendo Wii. 2011. 85f. Dissertação (Mestrado) - Programa de Pós-Graduação Interunidades Bioengenharia - Escola de Engenharia de São Carlos / Faculdade de Medicina de Ribeirão Preto / Instituto de Química de São Carlos da Universidade de São Paulo, São Carlos, 2011.

A população mundial está envelhecendo e as mudanças no perfil, características e funcionalidade própria dos sujeitos idosos geram impacto no desenvolvimento de produtos, nos serviços de cuidados de saúde e assistência social. Durante o processo de envelhecimento o idoso é exposto a diversos tipos de processos transformadores que podem ter impacto na capacidade funcional de forma que interfiram na realização das atividades da vida diária e na participação social. O equilíbrio é uma das habilidades que podem ser afetadas pelo envelhecimento. A atividade física específica auxilia a evitar quedas entre a população idosa. A relação entre a prática virtual de atividade física e o ganho real de habilidades motoras tem sido pesquisada em diversos estudos. A forma de interação dinamizada pelas interfaces como a do Nintendo Wii Fit desperta interesse na área da saúde. Objetivos: verificar os efeitos da prática virtual de posturas de Yoga sobre o controle postural de mulheres idosas ativas utilizando o software de vídeo game do Nintendo Wii Fit. Especificamente pretende-se verificar se houve alteração no equilíbrio postural estático após o período de intervenção e se o software é sensível à variação de desempenho do sujeito no decorrer da prática. Casuística: Seis mulheres idosas com idade média de 67,6, com escolaridade entre o ensino fundamental e superior, de diferentes religiões, procedentes de Ribeirão Preto e de classe socioeconômica média, sem patologias neurológicas, sensoriais ou ortopédicas associadas. Metodologia: Trata-se de um estudo exploratório, longitudinal, do tipo intervenção, que teve três etapas definidas: A primeira consistiu na triagem que incluiu a avaliação inicial do controle postural por meio da Escala de Equilíbrio de Berg (EEB), Timed Up and Go Test (TUG), Índice de Massa Corpórea (IMC), Escala de Depressão Geriátrica (GDS), Health Assessment Questionnarie (HAQ), teste de Romberg clássico e uma avaliação específica com 16 posições modificadas de Romberg sobre uma plataforma de força (PF). A segunda consistiu num protocolo de intervenção utilizando o Nintendo Wii com 14 posturas de Yoga sobre a plataforma Wii Balance Board, durante 2 meses com freqüência de 3x/semana com duração de 40 minutos. A terceira fase incluiu a reavaliação com os instrumentos EEB, TUG, Teste de Romberg modificado na PF e questionário de avaliação da satisfação dos sujeitos. Análise de Dados: estatística descritiva e inferencial. Os resultados sugeriram que houve uma melhora no controle postural para a realização das tarefas motoras e funcionais, melhora no tempo de percurso do equilíbrio dinâmico. Os testes selecionados foram sensíveis a detecção de alterações do equilíbrio de idosos, levando-se em consideração que a população era ativa e praticante de atividade física.

Palavras-Chave: Controle postural, Idosos, Nintendo Wii, Gerontotecnologia 


\begin{abstract}
SOARES, F. A. C. L. The influence of Yoga's virtual practice over elderly womens postural control using the Nintendo Wii. 2011. 85f. Dissertação (Mestrado) - Programa de Pós-Graduação Interunidades Bioengenharia - Escola de Engenharia de São Carlos / Faculdade de Medicina de Ribeirão Preto / Instituto de Química de São Carlos da Universidade de São Paulo, São Carlos, 2011.
\end{abstract}

The world population is aging and the changes in profile, characteristics and functionality of the elderly to generate an impact on the development of products, in the health care systems and social assistance. During the aging process the elderly is exposed for a various types of transformers processes that may have impact in the functional capability in order to in the execution of daily living and in the social participation. The balance is one of skills that can be affected by aging. The specific physical activity helps prevent falls among elderly. The relationship between virtual practice of physical activities and the real gain of motor abilities has been researched in various studies. The interaction form promoted by the interfaces like the Nintendo Wii Fit generates great interest in the health area. Objectives: Check the effects of virtual practice of Yoga postures on postural control of active elderly woman using the software of the Nintedo Wii Fit video game. Specifically intended to check that had alteration in the postural balance after the intervention period and if the software is sensitive to variation of subject performance during the practice. Casuistry: Six elderly woman with an average age of 67,6, education level between basic and undergraduate, from different religions, coming from Ribeirão Preto and the middle socioeconomic class, without neurological, sensory or orthopedic patologies associates. Methodology: It is an exploratory, longitudinal, intervention type, which had three stages defined: The first consisted in the screening that included the initial assessment of postural control using the Berg Balance Scale (BBS), Timed Up and Go Test (TUG), Body Mass Index (BMI), Geriatric Depression Scale (GDS), Health Assessment Questionnarie (HAQ), Romberg classic test and a specific assessment with 16 positions modified of Romberg on a force platform (FP). The second consisted of a intervention protocol using the Nintendo Wii with 14 postures of Yoga on the Wii Balance Board plataform, during two months with frequency of 3x/week lasting 40 minutes. The third phase included a reassessment with the instruments BBS, TUG, the Romberg modified test on the FP and assessment questionnaire of subjects satisfaction. Data Analysis: descriptive and inferential statistics. The results suggested an improvement in postural control for the performance of functional motor tasks, improvement in the passage time of dynamic balance. The selected tests were sensitive by detecting changes in the elderly balance, considering that the population was active and practicing physical activity.

Keywords: Postural Balance, Elderly, Nintendo Wii, Gerontechnology. 


\section{LISTA DE FIGURAS}

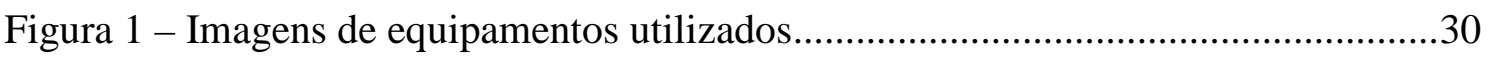

Figura 2 - Representação de um Estatocinesigrama ...................................................37

Figura 3 - Representação de um Estabilograma .........................................................37 


\section{LISTA DE GRÁFICOS}

Gráfico 1 - Pontuações obtidas pelos participantes em cada uma das 14

posições de Yoga fornecidas pelo Nintendo Wii Fit........................... 40 


\section{LISTAS DE QUADROS}

Quadro 1 - Descrições de posições efetuadas no estudo .............................................. 33

Quadro 2 - Posturas de Yoga segundo a seqüência pré programada pelo Nintendo 34 Wii com as siglas de identificação das posições

Quadro 3 - Caracterização dos sujeitos quanto às complicações de saúde e 39 características das práticas físicas

Quadro 4 - Caracterização dos sujeitos quanto à capacidade funcional e Índice de 40 Massa Corporal (IMC) 


\section{LISTAS DE TABELAS}

Tabela 1 - Dados da média e desvio padrão dos 6 participante na 2a $2^{\mathrm{a}} 12^{\mathrm{a}}$ e $24^{\mathrm{a}}$ sessão..42

Tabela 2 - Comparações entre pré e pós intervenção na plataforma de força ................45

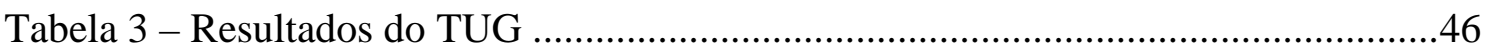

Tabela 4 - Média da pontuação de Berg em cada um dos grupos de tarefas ..................46 


\section{LISTA DE SIGLAS}

AP: Anteroposterior

AVDs: Atividades de vida diária

AVE: Acidente vascular encefálico

CG: Centro de gravidade

$\mathrm{CH}$ : Chair

CIR - HE: Centro Integrado de Reabilitação - Hospital Estadual

DB: Deep Breathing

DD: Dance direita

DE: Dance esquerda

DFD: Downward facing Dog

DHI: Dizziness Handicap Inventary

ECEU: Espaço de cultura e extensão universitária

EEB: Escala de Equilibrio de Berg

GD: Gate direita

GDS: Geriatric Depression Scale

GE: Gate esquerda

GV: Grounded V

HAQ: Health Assessment Questionnarie

HMD: Half Moon direita

HME: Half Moon esquerda

IMC: Índice de Massa Corporal

ML: Médiolateral

PF: Plataforma de força

PT: Palm Tree

RV: Realidade Virtual

SED: Spine Extension direita

SEE: Spine Extension esquerda

SKD: Standing Knee direita

SKE: Standing Knee esquerda

SS: Sun Salutation

TCLE: Termo de concentimento livre e esclarecido

TD: Tree direita

TE: Tree esquerda

TrD: Triangle direita

TrE: Triangle esquerda

TUG: Timed Up and Go Test

UDESC: Universidade do Estado de Santa Catarina

UNICID: Univesidade Cidade de São Paulo

WD: Warrior direita

WE: Warrior esquerda 


\section{SUMÁRIO}

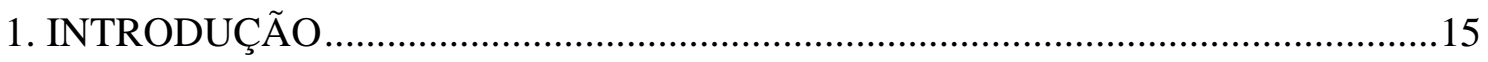

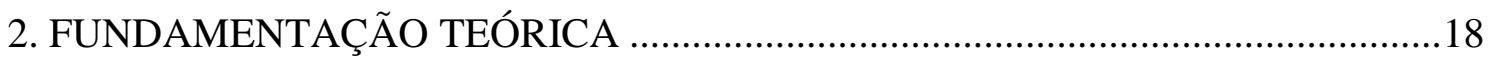

$2.1 \mathrm{O}$ impacto do envelhecimento sobre o controle postural .......................................18

2.2 A Influência da atividade física no equilíbrio de idosos ..........................................19

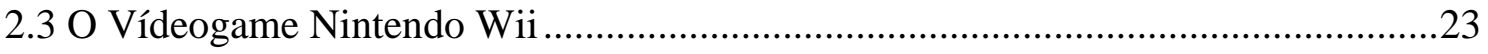

2.4 Nintendo Wii Fit no Equilíbrio Postural..................................................................24

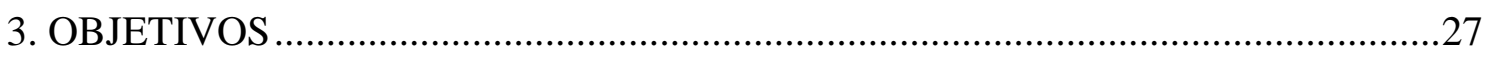

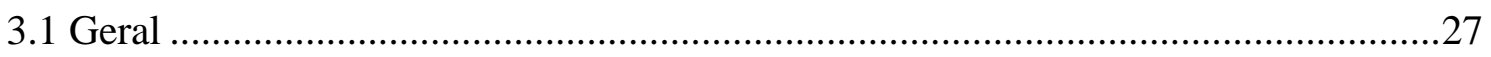

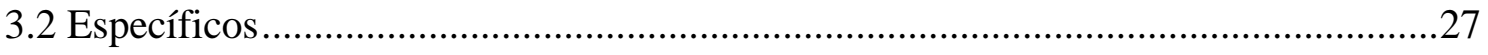

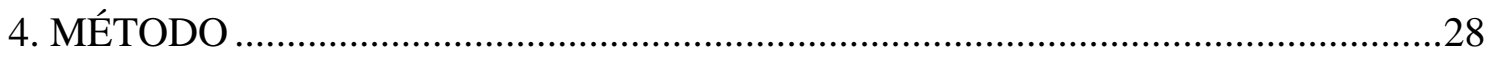

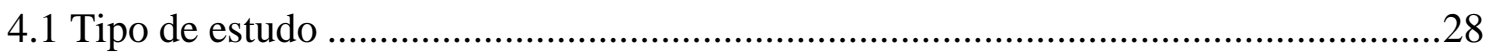

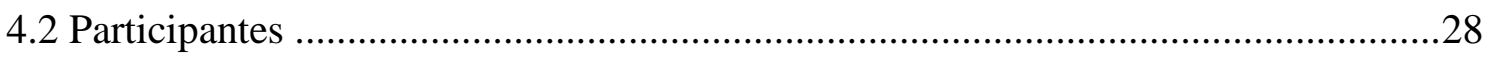

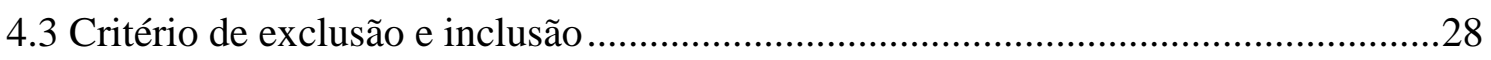

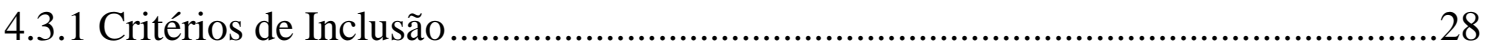

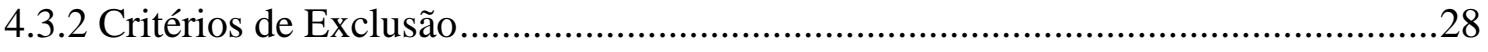

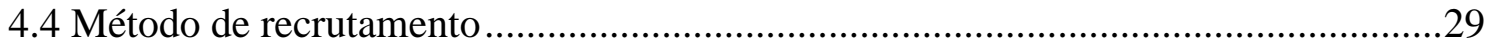

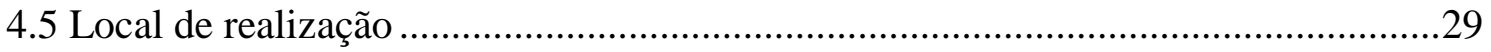

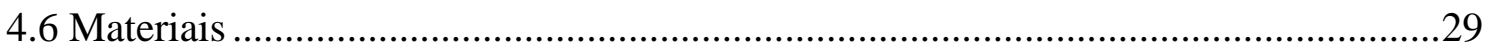

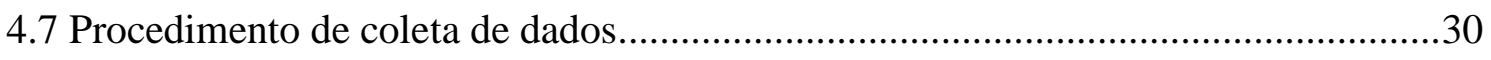

4.7.1 Descrição dos testes da fase de triagem..............................................................30

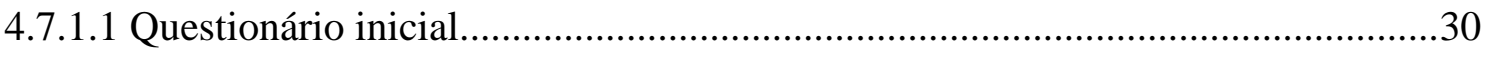

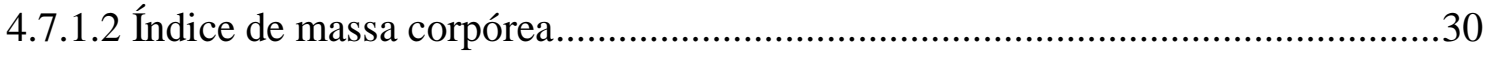

4.7.1.3 Dizziness Handicap Inventary ….........................................................................

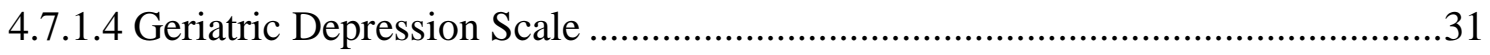

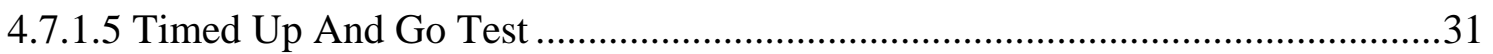

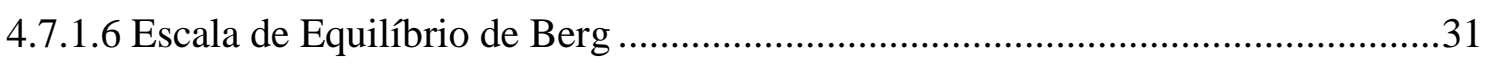

4.7.1.7 Health Assessment Questionnarie ...................................................................

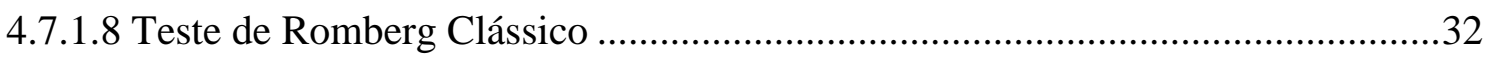

4.7.2 Descrição dos testes da fase de avaliação pré intervenção..................................33 
4.7.2.1 Teste de Romberg modificado sobre a Plataforma de Força-PF (dezesseis posições

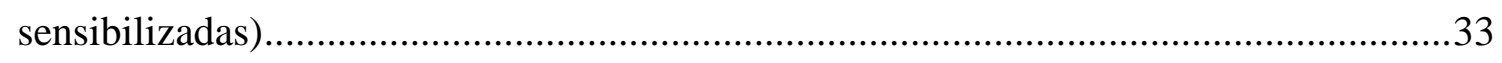

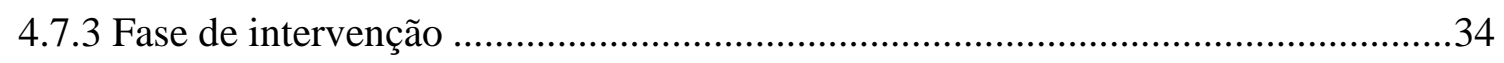

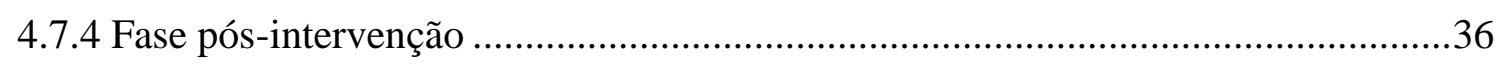

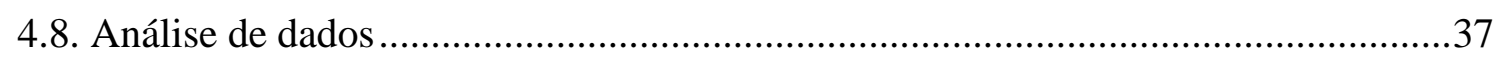

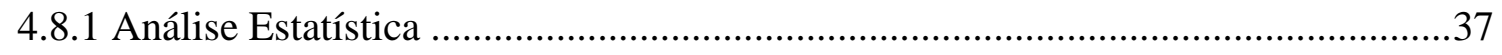

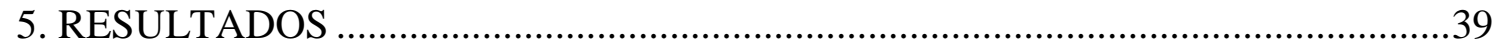

5.1 Dados de caracterização dos sujeitos.....................................................................39

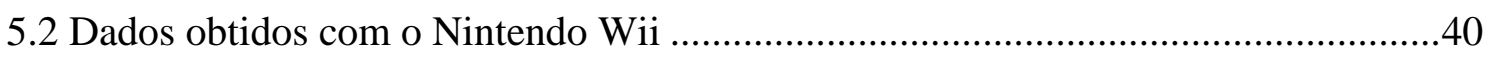

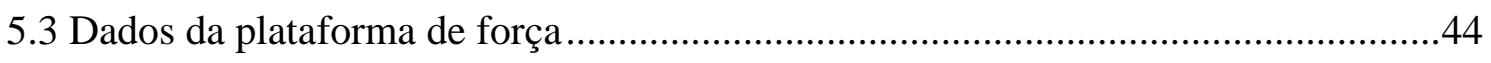

5.4 Dados do Timed Up and Go Test (TUG) ...........................................................46

5.5 Dados da Escala de Equilíbrio de Berg (EEB) ........................................................47

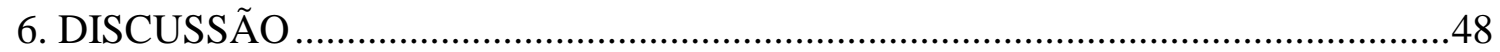

6.1 Discussão sobre o protocolo de seguimento proposto..............................................49

6.2 Discussão sobre os efeitos da prática com o Nintendo Wii Fit .................................49

6.3 Discussão quanto ao questionário de satisfação do sujeito

6.4 Discussão sobre a sensibilidade do software frente à variação de desempenho do sujeito no decorrer da prática............................................................................50

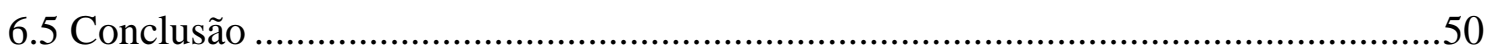

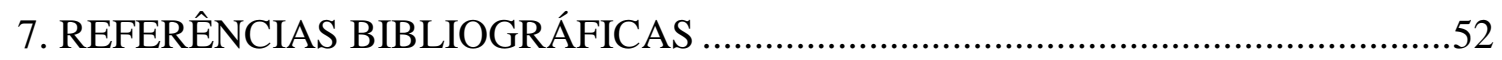

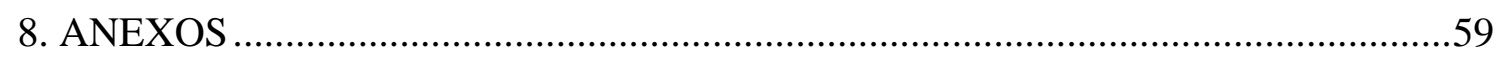




\section{INTRODUÇÃO}

A segunda metade do século XX e o início do XXI assistiram a grandes avanços na área da medicina com relevante enfoque nas condições sócio-sanitárias. Tais condições propiciaram condições para a redução de diversas patologias, fazendo com que as pessoas não sucumbissem a enfermidades que antes eram potencialmente letais. Além disso, a crescente diminuição das taxas de fecundidade e mortalidade em diversos países do mundo, inclusive no Brasil associado à urbanização, geraram o aumento da expectativa de vida e, como consequencia, a inversão das pirâmides etárias, antes constituídas principalmente de crianças e jovens. (LIMA, 2005; ARAÚJO, 2007)

Em pesquisa sobre as características da população brasileira realizada pelo censo de 2010, foi verificado que o Brasil possui uma população de quase 13 milhões de idosos, cerca de 7,4\% da população absoluta brasileira (IBGE, 2010). Estes dados apontam a grande necessidade de pesquisas que tenham como alvo o envelhecimento e as políticas públicas voltadas para esta população, visando à diminuição de gastos com o sistema de saúde, identificando e eliminando fatores que aceleram o processo de incapacitação, com vistas a elaborar políticas consistentes com suas reais necessidades e proporcionar melhor qualidade de vida à população idosa.

Durante o envelhecimento o idoso é exposto a diversos tipos de processos degenerativos e debilitantes transformadores que podem ter impacto na capacidade funcional. Esses processos deliberadamente interferem na realização das atividades da vida diária tanto as básicas quanto as instrumentais e influenciam a participação social do idoso nos diversos contextos de vida.

O equilíbrio é uma das habilidades que podem ser afetadas diretamente no processo de envelhecimento (AGUIAR et al, 2008). O equilíbrio ou controle postural pode ser compreendido como a configuração das articulações de um corpo, isto é, o conjunto de ângulos que expressam o arranjo relativo entre os segmentos de um corpo (ZATSIORSKY, 1998). O equilíbrio está relacionado à integridade de três principais capacidades do ser humano: visão, propriocepção e sistema vestibular (PERRACINI, 2002).

Essas capacidades lançam informações importantes para o sistema muscular reagir às perturbações tanto de ordem interna quanto de ordem externa. Tais informações são interpretadas pelo sistema muscular que faz a correção em tempo hábil a fim de propiciar o controle postural funcional. 
Para que a musculatura responda a exigência solicitada é importante que esteja com suas funções preservadas.

No entanto, a perda gradual de tecido muscular, denominado sarcopenia, pode ser observada na velhice, e afeta uma das variáveis o controle do equilíbrio. Tais mudanças ocorrem, principalmente, pela diminuição das fibras do tipo II (fibras de contração rápida) sendo esta redução em uma taxa maior do que a diminuição das fibras do tipo I (fibras de contração lenta) (CARTEE, 1994; PORTER VANDERVOORT; LEXELL, 1995).

Essas fibras musculares consumidas são substituídas por tecido gorduroso ou conectivo, dando ao músculo um caráter fibroso mais rígido. Pelo fato das fibras do tipo II serem responsáveis pela rápida resposta do corpo a estímulos internos e externos esse pode ser o motivo pelo qual o idoso tem dificuldades em responder rapidamente aos estímulos de correção da postura (ANIANSSON; GRIMBY; HEDBERG, 1992; KENT-BRAUN \& YOUNG, 2000).

A perda de força muscular decorrente da sarcopenia gera um ciclo vicioso em que se apresentam a diminuição das atividades de vida diárias (AVDs), a perda da independência e o aumento do risco de quedas (WALSH, 2006).

Segundo Ovestall (2003) mais de um terço dos idosos acima de 65 anos sofrem quedas a cada ano. As chances de quedas aumentam com a idade, sendo de $32 \%$ de chance em idades entre 65 e 74 anos; 35\% entre 75 e 84 anos e 51\% acima dos 85 anos. Idosos com dificuldade em AVDs possuem 14 vezes mais probabilidade de cair do que aqueles que possuem a mesma idade (SILVA, et al. 2008).

O grau de estabilidade corporal depende diretamente de quatro fatores: peso do corpo, altura do centro de gravidade, tamanho da base de sustentação e a localização da linha de gravidade sobre a base de sustentação. A estabilidade é potencializada quando um baixo centro de gravidade associado a uma base ampla de sustentação, linha de gravidade no centro de apoio e um peso grande (SMITH et al, 1997).

Durante o processo de envelhecimento a base de suporte funcional, região onde o corpo se apóia ao chão, no caso, os pés não é alterada. Porém, o limite ao qual seu centro de gravidade (CG) pode se projetar, com tempo hábil de correção, sobre a base de suporte, diminui sensivelmente (FREITAS \& DUARTE, 2006). Esse tipo de mudança pode se relacionar ao fato do idoso não possuir resposta proprioceptiva rápida, e controle neuromuscular adequado a fim de corrigir seu equilíbrio.

Em vista das conseqüências que as quedas podem trazer para a vida do indivíduo idoso e para sua família, torna-se relevante discutir a questão do equilíbrio com a comunidade 
científica. Alguns estudos realizados nesta área apontam que a manutenção ou inserção da atividade física específica como meio de manter ou melhorar o controle postural auxilia a evitar quedas entre a população idosa (LUUKINEN et al., 1995; FEDER et al., 2000; RUBENSTEIN \& JOSEPHSON, 2002; JESEN et al., 2002; RYDWIK; FRANDIN; AKNER, 2004; OZGÜRBÜZ, 2003). Dessa forma, considera-se relevante que sejam cada vez mais aprofundados os estudos que envolvem a relação entre atividade física e envelhecimento.

Em minha prática profissional como fisioterapeuta, tenho lidado com a assistência a idosos com diversas alterações nas funções musculoesqueléticas e interessou-me o estudo sobre a utilização de novas tecnologias como o videogame para fins de intervenção na área da saúde. Além disso sou praticante de Yoga há 3 anos e tal prática me incitou a investigar os efeitos que sua execução virtual poderia ter na vida de sujeitos idosos. A participação junto ao grupo do Laboratório de Pesquisa em Inovação e Tecnologia Assistiva - LAPITEC da Faculdade de Medicina de Ribeirão Preto fez com que este interesse aumentasse e fizesse parte da discussão sobre as novas tendências e aplicação de recursos não convencionais no tratamento de pessoas com condições crônicas.

Assim, conhecer a influência da prática virtual de Yoga sobre o controle postural de mulheres idosas ativas utilizando o Nintendo Wii foi o objetivo principal deste estudo. As perguntas principais do estudo buscam identificar se o Nintendo Wii é sensível para detectar a alteração de equilíbrio comparado à avaliação na plataforma de força, se a melhora do desempenho na utilização do jogo corresponde a uma melhora real do controle postural e se a plataforma de força e os testes selecionados são sensíveis para detectar variações apresentadas pelo indivíduo avaliado após a intervenção.

Este estudo vem preencher uma lacuna no campo de conhecimento da área da saúde, especificamente na área de tecnologias clínicas e de reabilitação. No Brasil, são escassos os estudos relacionados à utilização de videogames e softwares interativos como o Nintendo Wii e a reabilitação de pessoas com alterações na funcionalidade. No exterior vários estudos tem sido desenvolvidos apontando os benefícios desta prática na complementaridade das intervenções tradicionais. A sistematização de um conjunto de dados avaliativos do controle postural de mulheres idosas e a utilização do Nintendo Wii num protocolo de intervenção pré-estabelecido pode servir como base de dados para futuros estudos e para a tomada de decisão do profissional de saúde na escolha de um programa de exercícios que possa funcionar como coadjuvante ao tratamento de alterações na funcionalidade e na prática de exercícios a ser desenvolvidos por pessoas idosas. 


\section{FUNDAMENTAÇÃO TEÓRICA}

2.1 O impacto do envelhecimento sobre o controle postural

Durante o processo de envelhecimento o idoso é exposto a diversos tipos de processos degenerativos e debilitantes transformadores. De maneira geral, a pele perde a elasticidade normal, os músculos perdem a capacidade de contrair-se de forma rápida e os ossos sofrem desmineralização. As medidas antropométricas, por consequência, também sofrem influência de tais efeitos durante o processo de envelhecimento. A altura é alterada na senilidade através de compressões vertebrais, desidratação dos discos intervertebrais, e da cifose torácica, deslocando o centro de gravidade e causando diminuição da mobilidade. Já o peso é tido como um fator afetado, entre outras coisas, pela alimentação, sedentarismo, alcoolismo e tabagismo (MATSUDO, 2002).

A manutenção do equilíbrio do corpo é composta pelas funções dos sistemas nervoso, sensorial e motor. O sistema sensorial fornece informações sobre a posição de segmentos corporais em relação a outros segmentos e ao ambiente. O sistema motor e responsável pela ativação correta e adequada de músculos para realização dos movimentos. O sistema nervoso central integra informações provenientes do sistema sensorial para, então, enviar impulsos nervosos aos músculos que geram respostas neuromusculares adequadas as correções posturais (DUARTE \& FREITAS, 2010).

Em um estudo sobre as condições de reação em situações de desequilíbrio Ahmed e Ashton-Miller (2005) buscaram detectar se a idade cronológica tem influência na tarefa corporal de detecção de erros e respostas compensatórias que levam à queda. Para isso, dois grupos, o primeiro com 20 jovens e o segundo com 20 idosos foram convidados a se equilibrar em uma cadeira de balanço pelo maior tempo possível. A condição de aceleração descontrolada da cadeira foi detectada nos dois grupos. No entanto, enquanto jovens demoram mais a responder ao desequilíbrio os idosos respondem mais rapidamente, sugerindo um maior controle reflexo por parte dos jovens.

Para melhor compreender os fatores intrínsecos que predispõem o indivíduo a queda, é necessário entender as forças envolvidas no controle do equilíbrio na velhice. Um conceito associado à base de suporte e o de limite de estabilidade, o qual expressa o quanto dessa base de suporte o individuo consegue utilizar e se manter em equilíbrio, isto e, os limites de estabilidade expressam a base de suporte funcional do individuo. Durante o processo de envelhecimento o limite ao qual seu centro de gravidade (CG) pode se projetar, 
com tempo hábil de correção, sobre a base de suporte, diminui (FREITAS \& DUARTE, 2006).

O deslocamento do CG é a grandeza que realmente indica a oscilação do corpo inteiro, sendo a grandeza do centro de pressão (CP), na verdade, uma combinação da resposta neuromuscular ao deslocamento do CG e da própria posição do CG.

\subsection{A Influência da atividade física no equilíbrio de idosos}

As atividades físicas geram diversas melhorias às condições físicas e psicológicas de quem as praticam com alguma freqüência. Formas mais simples de exercícios, como a caminhadas ou ginásticas aeróbicas, atuam de forma benéfica. Uma das formas mais simples de atividade física é a isometria. Amplamente utilizada em reabilitação de lesões na fisioterapia, a isometria consiste em uma contração muscular sem que aja movimentação. Diversos estudos usam a atividade isométrica relacionada ao equilíbrio de idosos com resultados positivos. Entre os tipos mais comuns de atividade física isométrica mantida está o Yoga (AVEIRO et al., 2004; ALVES, et al., 2006).

De acordo com Bastille e Gill-Body (2004), o Yoga segue, basicamente, oito comportamentos básicos em suas práticas, todos focados no conceito holístico de tratamento somático e psicológico. Estes oito comportamentos são: yamas (disciplina moral), naiyamas (auto-contenção), pranayamas (controle respiratório), asanas (posturas físicas), pratyahara (inibição sensorial), dharana (concentração), dhyana (meditação), e samadhi (estado beatífico). A fim de estabelecer um foco sobre o equilíbrio, lançamos nosso olhar sobre o que diz respeito aos asanas (posturas físicas), deixando qualquer outra faculdade em segundo plano.

Tran et. al. (2001), utilizando técnicas de hatha Yoga em adultos saudáveis, verificaram aumento da força muscular, do torque de membros superiores e inferiores, da flexibilidade de ombros, tornozelos e coluna, e aumento da capacidade aeróbica.

Krishnamurthy e Telles (2007) avaliaram a influência da prática de Yoga e da medicina poli-ervas Ayurvédicas nas medidas de marcha, equilíbrio e mobilidade em idosos sedentários. Participaram do estudo 69 sujeitos que divididos em 3 grupos com o mesmo número de participante. Um dos grupos faria práticas de Yoga, outro grupo utilizaria a medicina poli-ervas e o terceiro grupo seria controle. Após 6 meses de intervenção constatouse aumentos significativos em todos os dados da marcha e do equilíbrio apenas no grupo que 
fez práticas de Yoga. Assim, os autores concluíram que a prática de Yoga promove a melhora da mobilidade articular e da força muscular.

Chen et al. (2010) realizaram um estudo para verificar as conseqüências que 24 semanas de Yoga teriam no condicionamento físico de idosos. Participaram deste estudo 69 idosos, os quais foram divididos em dois grupos - um que participou da intervenção e um grupo controle. Ambos foram avaliados quanto à flexibilidade, força muscular, equilíbrio e agilidade. O grupo que praticou Yoga realizou as atividades durante 24 semanas, sendo que as sessões ocorreram três vezes por semana e tinham duração de 70 minutos. Os resultados indicaram que o grupo que fez a prática de Yoga apresentou uma melhora significativa em todos os critérios sobre o grupo controle. Sendo assim, foi recomendado que exercícios de Yoga fossem incorporados em lares de assistência a fim de promover a aptidão física dos idosos.

Schimid et al (2010) buscaram investigar, em um grupo de idosos que apresentava medo de cair, quais seriam os efeitos de 12 semanas de prática de Yoga, com freqüência de 2 vezes por semana. Após avaliação foi constatada uma melhora do equilíbrio de $4 \%$ dos participantes, e o medo de cair diminui em 6\% deles. Os autores concluíram que o Yoga pode ser uma intervenção promissora para gerenciar o medo de cair e melhorar o equilíbrio, reduzindo assim o risco de quedas para o idoso.

O Tai Chi é uma prática que esta associada a manutenção de posturas por um período de tempo. Desta forma é possível correlacionar esta atividade a uma das formas de manutenção postural isométrica.

(Li et al., 2004) buscaram em seu estudo determinar se a possível melhora do equilíbrio funcional através da pratica constante de Tai Chi esta relacionada com redução de quedas. Ao total 256 idosos participaram de 6 meses de pratica de Tai Chi ou de exercícios de alongamento como controle. Como resultado foi constatado que os praticantes de Tai Chi que conseguiram melhorar seu equilíbrio funcional reduziram o risco de quedas quando comparados ao grupo controle.

Outros autores buscaram investigar a ligação entre diferentes tipos de atividades com idosos saudáveis. No estudo de Tsang e Hui-Chan (2004) foi investigada a influência da prática de Tai Chi no equilíbrio de pessoas idosas saudáveis. No estudo, 49 idosos realizaram sessões de 1h30min de Tai Chi, com uma freqüência de 6 vezes por semana, sendo que o equilíbrio dos participantes foi avaliado na $4^{\mathrm{a}}$ e $8^{\mathrm{a}}$ semana através de posturografia dinâmica computadorizada. Os autores concluíram que apenas 4 semanas foram, nessas condições, eficientes para melhorar o controle postural do idoso. 
Formas tradicionais de atividades foram avaliadas por diversos autores com resultados positivos. Mesmo não contendo exercícios isométricos, a prática regular de exercícios, em intervalos de tempos e sessões pré determinadas foram analisados.

Bellew et al. (2005) que verificaram o efeito de um treino de curta duração no equilíbrio dinâmico de mulheres idosas saudáveis. Participaram do estudo 21 mulheres, as quais foram divididas em 2 grupos: um grupo controle e um grupo que foi exposto a intervenções físicas resistidas durante 5 semanas, com freqüência de 2 vezes por semana e duração de 15 minutos cada sessão. Foi verificado que o grupo em que as mulheres participaram da atividade apresentou uma melhora de $25 \%$ do alcance funcional a frente dos membros superiores direito e esquerdo e $16 \%$ no alcance de membros inferiores.

Persch et al. (2009) buscaram determinar os efeitos do fortalecimento de membro inferior nos parâmetros cinemáticos da marcha associados ao risco de quedas de mulheres idosas. Para tanto, participaram 27 mulheres divididas em dois grupos. Um deles era experimental, e possuía 14 indivíduos que fizeram treinamento de fortalecimento com carga crescente ao longo de 12 semanas, com freqüência de 3 vezes na semana. O outro grupo era para controle, composto por 13 indivíduos que não realizaram nenhuma atividade. Nos parâmetros de força muscular avaliados, e nos parâmetros cinemáticos relacionados a quedas houve melhora significativa do grupo que efetuou o protocolo de intervenção.

Hatzitaki et al. (2009b) verificaram o impacto de treinos de mudança de peso no equilíbrio de mulheres idosas saudáveis. No estudo, 48 indivíduos foram divididos em 3 grupos. O grupo 1 treinou mudanças de peso no sentido anteroposterior, o grupo 2 treinou mudanças de peso no sentido médiolateral e o grupo 3 foi o controle. As sessões foram realizadas três vezes por semana, com duração de 25 minutos cada. No total, foram realizadas 12 sessões. Os resultados indicaram que na avaliação bipodal estática não houve melhoras significativas entre ambos os grupo de intervenção, porém quando comparados os valores gerados pelos testes de Romberg, observou-se uma diminuição da oscilação corporal do grupo que treinou a mudança de peso na direção anteroposterior.

Granacher et al. (2009) investigaram os efeitos do treinamento de resistência na performance de força e no controle postural de idosos. Participaram 40 indivíduos saudáveis divididos em grupo intervenção e grupo controle. O treinamento consistia em um trabalho de força a $80 \%$ da força máxima. Os participantes foram avaliados antes e após as 13 semanas de treinamento. Os autores constataram uma melhora significativa em todos os testes avaliados, com exceção do teste de perturbação em plataforma, sugerindo que o treinamento não foi sensível para treinamento do controle postural. 
Gauchard et al. (2003) avaliaram o impacto de dois tipos distintos de atividades na aferência visual e nos diferentes parâmetros de regulação do equilíbrio estático. Um total de 44 mulheres foi avaliado, das quais 15 pertenciam a um grupo onde se praticavam atividades proprioceptivas, 12 pertenciam a um grupo que praticava atividades bioenergéticas, e 18 formavam o grupo controle. Como resultado observou-se que o grupo que praticava exercícios proprioceptivos teve menor deslocamento de área nos testes realizados tanto com os olhos abertos quanto com os olhos fechados. O grupo controle apresentou o maior valor de área de deslocamentos. E o grupo com as mulheres que praticavam exercícios bioenergéticos tiveram índices parecidos com o grupo proprioceptivo com os olhos abertos e com o grupo controle quando avaliadas com os olhos fechados. Portanto, embora o grupo de atividades bioenergéticas tenha tido melhora em atividades simples, nas tarefas posturais mais difíceis mostraram que esse tipo de atividade não desenvolve um limite de entrada neurosensorial proprioceptivo, provavelmente devido a maior contribuição dos aferentes visuais.

Outras modalidades de intervenção, aquelas assistidas por computador, geram diferenciais no que diz respeito a biofeedback, isto é, feedback facilitado por um meio externo, gerando informações sensoriais para a adequação a atividade realizada. Esse tipo de tecnologia, incluindo ai a realidade virtual (RV) já vem sendo empregado por vários estudos.

Lindemann et al. (2004) realizaram um estudo que comparava um programa de exercícios físicos feitos em casa com um treinamento de equilíbrio assistido por computador. Participaram do estudo 24 idosos saudáveis, fisicamente ativos. O desempenho mensurado nos participantes incluiu a estabilidade corporal enquanto sentado, subindo degraus, andando, e o alcance funcional. Através destas variáveis, o equilíbrio dos participantes foi avaliado por um placar que continha o resumo do desempenho de cada idoso. Os resultados indicaram que os sujeitos que fizeram o treinamento assistido pelo computador melhoraram seu desempenho, tanto na evolução das atividades propostas pelo treinamento quanto no placar de desempenho de equilíbrio. O grupo que fez o programa caseiro não apresentou melhoras em nenhum dos itens avaliados. Assim, os autores sugerem que o sistema de biofeedback atua como uma supervisão, aumentando a eficiência nos exercícios físicos em indivíduos idosos.

Hatzitaki et al. (2009a) verificaram os efeitos da prática de deslocamento de peso visualmente guiada em mulheres idosas enquanto evitam colisão em obstáculos, estando na posição em pé. Neste estudo, 56 mulheres idosas saudáveis foram divididas em 3 grupos. O grupo 1 foi submetido a 12 sessões de 25 minutos, 3 vezes por semana, praticando o desvio em direção anteroposterior; o grupo 2 procedeu da mesma maneira, porém praticando o desvio em direção mediolateral; e o grupo 3 foi controle. Os resultados indicaram um 
aumento da velocidade do tronco durante a fuga no grupo que praticou desvios na posição anteroposterior, enquanto o grupo 2 não apresentou melhoras. Os autores afirmam que a utilização de feedback visual é essencial para a otimização da mudança adequada de peso durante desvio dos obstáculos o que corrobora com o que a presente pesquisa, que busca mostrar que o biofeedback orientado visualmente ajuda na orientação espacial de mulheres idosas.

Esta revisão da literatura indica, principalmente, a relação existente entre a prática de atividades físicas durante a velhice e a melhora de habilidades ligadas ao equilíbrio. Foi direcionado, nesse estudo, pesquisas que investigaram, em particular, a prática do Yoga e os possíveis benefícios que ela pode trazer para a saúde e qualidade de vida da pessoa idosa, assim como novas tecnologias que são usadas a fim de assistir e facilitar a intervenção, como por exemplo a realidade virtual (RV).

\subsection{O Vídeogame Nintendo Wii}

Com a evolução da tecnologia o ser humano se tornou cada vez mais sedentário, buscando formas mais inertes de diversão, gerando grande preocupação na comunidade científica ligada à área da saúde. Por esse motivo novas tecnologias estão sendo desenvolvidas a fim de unir a inovação da tecnologia com a dinamização de suas abordagens. Tal proposta trouxe a tona interfaces mais interativas aos videogames atuais.

A forma de interação dinamizada pelas interfaces como a do Nintendo Wii Fit é de grande interesse a área da saúde, pois exige dos utilizadores habilidades requeridas em atividades cotidianas para a sua utilização. Posições como o apoio bipodal simples, bipodal com bases afastadas, posturas com a cabeça invertida, inclinações de tronco, apoio unipodal, apoio em ponta de pé, entre outras.

Outro fator positivo para o Nintendo Wii são os dados quantitativos fornecidos ao software durante a programação das atividades virtuais. Dados como o de Índice de Massa Corpórea (IMC) e os objetivos estipulados pelo jogo fornecem incentivos à continuação das práticas (PIERCE, 2008).

Em uma visão mais abrangente sobre o tema podemos considerar o fato de que alguns idosos possuem uma aversão maior, quando comparados a indivíduos jovens, a aparelhos eletrônicos, o que pode por muitas vezes gerar dificuldades de interação entre esses indivíduos e a realidade virtual. 
Pelo fato de a interface do jogo promover a destreza física como forma de interação há nesse tipo de realidade virtual a presença do elemento dinâmico ao invés da motricidade fina e detalhada de outros tipos de controladores.

A brincadeira é um elemento lúdico da cultura, que pode proporcionar uma riqueza de sentimentos que tem a possibilidade de traduzir-se em prazer, satisfação, alegria, vontade de viver, amor próprio e autoconfiança (MATOS, 2006). Podemos promover a brincadeira com o Wii de uma maneira virtual, gerando competição, interesse em melhorar sua pontuação, auto-superação e secundariamente a esses objetivos conseguir promover a melhora das faculdades físicas durante a prática de Yoga do Nintendo Wii Fit. Esses atrativos podem vir a contribuir para que possamos aproximar essa nova visão de tecnologia com a população.

Nesse sentido foram realizados estudos por McCann (2009) e Czarnecki (2007) que compararam diversos tipos de vídeo game. Sendo o Nintendo Wii o mais citado no quesito interesse na população adulta, justamente por propiciar o envolvimento da família e a reunião de pessoas de diferentes idades ao redor de melhorar suas performances em jogos controlados pelo controle postural.

\subsection{Nintendo Wii Fit no Equilíbrio Postural}

Diversos autores têm tentado relacionar a pratica virtual de atividade física ao ganho real de habilidades motoras.

Kim et al. (2009) mostraram melhora do equilíbrio postural estático e dinâmico em grupos em que foi adicionado 30 minutos extras de realidade virtual às sessões de 40 minutos de fisioterapia convencional, por 4 vezes por semana durante 4 semanas.

Clark e Kraemer (2009) examinaram a efetividade de uma nova interação de vídeo games que visa resolver disfunções de risco de quedas de um idoso institucionalizado. O sujeito em questão possuía 89 anos, disfunção inespecífica de equilíbrio e histórico de múltiplas quedas. Foi realizado treinamento de boliche com o Nintendo Wii para trabalhar o equilíbrio. Após 6 sessões de uma hora ele evoluiu de 48 para 53 na Escala de Equilíbrio de Berg (EEB) e de 14,9s para 10,5s no Timed Up and Go Test.(TUG) Conclui-se portanto que a fisioterapia usando o Nintendo Wii boliche pode ter diminuído o risco de quedas para esse indivíduo.

Saposnik et al. (2010a) buscaram em seu estudo verificar a efetividade de exercícios em realidade virtual para reabilitação de pessoas que sofreram acidente vascular 
encefálico (AVE) com ênfase em membros superiores após 2 meses do ocorrido. Um total de 22 sujeitos foram randomizados e divididos em 2 grupos distintos, sendo um com atividades com o Nintendo Wii e outro grupo realizou terapia recreacional. Após 4 semanas foram reavaliados gerando um total de 388 minutos no grupo de recreação e 364 minutos do grupo do Wii. Ao final concluiu-se que a realidade virtual utilizando o Nintendo Wii representou uma alternativa segura, viável e potencialmente eficaz de recuperação motora pós AVE.

Saposnik et al. (2010b) em outro estudo buscaram verificar a eficácia da realidade virtual (RV) na reabilitação de membro superior pós acidente vascular encefálico (AVE) utilizando 2 grupos por 2 meses. Um grupo realizou atividades usando o Nintendo Wii e o segundo grupo fez uso de terapia recreacional. Concluiu-se que a realidade virtual do Wii representa uma forma segura, viável e potencialmente efetiva na reabilitação motora pós AVE.

Gonzáles-Fernández et al. (2010) verificaram se a configuração do iBAVIR (sistema de baixo custo parecido com Wii Balance Board, desenhado para treino de equilíbrio) pode ser aplicada em centros de reabilitação virtual. Foram utilizados 2 grupos, um que usou o Wii e um que usou exercícios tradicionais de reabilitação, obtendo-se resultados encorajadores para o uso dessa nova tecnologia.

Yong Joo et al. (2010) avaliaram a viabilidade do uso do Wii junto com reabilitação convencional de pacientes pós AVE com fraqueza de membros superiores. 20 sujeitos com 3 meses de AVE foram submetidos a 6 sessões de Wii para membros superiores adicional a reabilitação convencional. Todos os 16 sujeitos que terminaram o programa comparam, ou preferiram o uso do Wii a terapia convencional.

Higgins et al. (2010) verificaram a percepção dos idosos institucionalizados sobre a utilização do Nintendo Wii em seus centros. Foi observado que o Wii foi de fácil dominação para os clientes mais capazes e que havia risco mínimo para os clientes. Funcionários relataram promoção da saúde e benefícios como mobilidade, amplitude de movimento, coordenação motora, habilidade e desafios.

Graven et al. (2010) compararam o gasto de energia e o grau de divertimento de 3 grupos distintos (adolescentes, adultos jovens e adultos idosos) frente a games do Nintendo Wii Fit (Yoga, fitness e equilíbrio), vídeo game manual e uma esteira. Quanto ao gasto energéticos o Wii ficou em segundo lugar perdendo apenas para a esteira. Quanto à diversão o Wii foi o que teve maior aceitação. Conclui-se que o Wii aparece como uma opção de exercício leve e moderado. 
No Brasil está sendo utilizado nas clínicas-escola da Universidade Cidade de São Paulo (UNICID), na Universidade do Estado de Santa Catarina (UDESC) e na UNOESTE de Presidente Prudente.

O presente estudo visa demonstrar as possibilidades de uso do Nintendo Wii Fit quando aplicado sob a óptica do trabalho com equilíbrio em idosos. Em razão da face lúdica, interatividade e do baixo custo do Nintendo Wii Fit em comparação a outras formas de terapias de equilíbrio, viu-se a necessidade de análise das características de seus componentes para esse fim. 


\section{OBJETIVOS}

3.1 Geral

O objetivo desse estudo foi verificar os efeitos da prática virtual de posturas de Yoga sobre o controle postural de mulheres idosas ativas utilizando o software de vídeo game do Nintendo Wii Fit.

\subsection{Específicos}

1- Verificar se houve alteração no equilíbrio postural estático após o período de intervenção.

2- Verificar se o software foi sensível à variação de desempenho do sujeito no decorrer da prática. 


\section{MÉTODO}

4.1 Tipo de estudo

É um estudo exploratório, longitudinal, do tipo intervenção.

\subsection{Participantes}

Participaram do estudo um total de 6 mulheres idosas ativas, com idade entre 60 e 75 anos (média 67,6) com escolaridade entre o ensino fundamental e superior, de qualquer religião, procedentes de Ribeirão Preto e de e classe socioeconômica média.

4.3 Critério de exclusão e inclusão

4.3.1 Critérios de Inclusão

- Idosos que aceitaram participar do estudo.

- Ausência de quaisquer patologias neurológicas, cognitivas, psicoafetivas, ortopédicas e vestibulares diagnosticadas

- Ausência de tonturas, déficit auditivo ou quedas recentes (6 meses).

\subsubsection{Critérios de Exclusão}

- Participantes que possuíam alterações neurológicas, psicoafetivas, ortopédicas, sensoriais, vestibulares ou cognitivas que impedissem ou limitassem a execução das atividades propostas.

- Participantes que apresentaram IMC acima de $30 \mathrm{Kg} / \mathrm{m}^{2}$ (sobrepeso acentuado).

- Sujeitos submetidos a cirurgias recentes que interferissem na função sensório motora.

- Participantes que tivessem iniciado atividades físicas e esportivas há menos de 2 meses.

- Participantes que não cumpriam os critérios exigidos nos testes de triagem (descritos no item A dos procedimentos de coleta de dados).

Este grupo participou das etapas de triagem, avaliação inicial, protocolo de intervenção e avaliação final.

O grupo contou com 6 integrantes que passaram pelo processo de triagem e pelas avaliações posturais antes e após o protocolo de intervenção de 24 sessões sendo 8 semanas por 3 vezes a semana com o Nintendo Wii.

Estudos com desenhos de protocolos semelhantes ao usado por este estudo foram buscados na literatura com indicação de resultados positivos quanto ao ganho de controle 
postural (RUNGE; REHFELD; RESNICEK (2000); GIL-GOMEZ et al. (2011); MOUWAD et al. (2011); NITZ et al. (2010).

\subsection{Método de recrutamento:}

Inicialmente foram selecionados 58 indivíduos. Sendo 51 mulheres e 7 homens. Destes 11 desistiram logo depois de organizado os grupos e explicado os procedimentos a serem tomados. 14 alegaram que viajariam em breve ou que tinham que viajar com freqüência por isso não poderiam participar com assiduidade da intervenção. 12 possuíam problemas agravados de visão o que excluiria a possibilidade de realizar os exercícios propostos com segurança. 4 possuíam histórico de AVE com algum tipo de seqüela motora ou cognitiva. 3 participante apresentaram o GDS-15 acima da nota de corte, o que confere dizer que apresentam indícios de depressão. 3 apresentam IMC acima do corte de $30 \mathrm{~kg} / \mathrm{m}^{2}$. 3 apresentaram problemas de audição associado a tontura com nota de corte acima dos 30 pontos propostos pelo DHI. Ainda um sujeito apresentava Alzheimer e outro estava acima da idade proposta para o grupo, de 60 a 75 anos.

Os sujeitos foram abordados diretamente nos projetos de Inclusão Digital do Idoso e da Oficina da Memória que acontece no campus da USP - Ribeirão Preto (rua das Paineiras $n^{\circ}$ ) e no Espaço Cultural de Extensão Universitária da Faculdade de Medicina de Ribeirão Preto - ECEU/USP (Av. Nove de Julho, Centro), respectivamente.

Do total foram selecionados apenas 6 sujeitos que participaram por todo o processo de intervenção. Todos assinaram o Termo de Consentimento Livre e Esclarecido (TCLE).

4.5 Local de realização

Espaço Cultural de Extensão Universitária da Faculdade de Medicina de Ribeirão Preto - ECEU: Fase Triagem e Intervenção:

Centro Integrado de Reabilitação CIR-HE: Fase de avaliação do equilíbrio com a Plataforma de força.

\subsection{Materiais}

Os procedimentos de coleta de dados incluíram os seguintes equipamentos:

a) Plataforma de força EMG System do Brasil.

b) Wii Fit composto por Wii Balance Board e CD com jogos

c) Nintendo Wii (console e controles) 
d) Fita métrica

e) Cronômetro

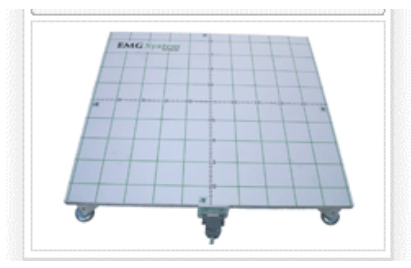

(a)

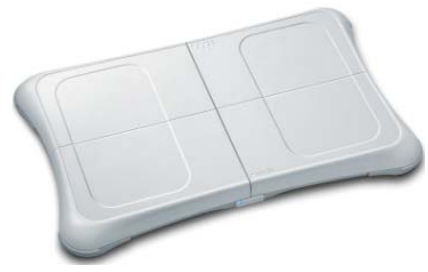

(b)

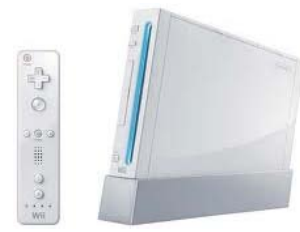

(c)

Figura 1 - Imagens de equipamentos utilizados

4.7 Procedimento de coleta de dados

\subsubsection{Descrição dos testes da fase de triagem}

\subsubsection{Questionário inicial}

O questionário inicial (ANEXO A) é um questionário semi-estruturado que buscou informações pessoais a fim de padronizar a amostra selecionada para a pesquisa. Foi aplicado em forma de perguntas diretas ao voluntário com questões relativas à idade, tipo de atividade física, tempo de prática, aspectos relacionadas à saúde, limitações ou dor ao movimento, comprometimentos sensoriais, uso de dispositivo de auxílio à função (tecnologia assistiva), queda recentes, etc.

Foram utilizados os seguintes critérios de exclusão: caso o participante tenha iniciado prática física há menos de 2 meses (o que foi considerado uma variável de confusão uma vez que ainda poderia estar num período de aquisição decorrente de prática física). Foi excluído também o participante que apresentou algum tipo de comprometimento auditivo, queda recente, patologias identificadas, dor ou dificuldade de movimento limitante, assim como cirurgia recente, tonturas ou desmaios com freqüência. Quando constatada a presença de tontura, o participante foi rastreado com o Dizziness Handicap Inventary-DHI.

\subsubsection{2 Índice de Massa Corpórea}

O índice de massa corpórea (IMC) é um índice que determina a massa do sujeito em relação ao peso. Para a determinação do IMC, foi calculado o peso dividindo-o pelo quadrado da altura. Foram excluídos os sujeitos que possuíam o IMC acima de 30 $\mathrm{Kg} / \mathrm{m}^{2}$ (sobrepeso acentuado) (ANEXO B). 


\subsubsection{Dizziness Handicap Inventary}

O Dizziness Handicap Inventary (DHI) é um questionário que quantifica o grau de tontura relatada. Contém 25 questões relacionadas à identificação do aumento da tontura em idosos em diversas situações do cotidiano. As opções de pontuação são de 0 para as resposta NÃO, 2 para ÀS VEZES, e 4 para SIM.

O participante foi excluído quando sua pontuação no teste exceder 30 pontos, até onde é considerada tontura leve (TRELEAVEN, 2006). (ANEXO C)

\subsubsection{Geriatric Depression Scale}

Geriatric Depression Scale (Escala de Depressão Geriátrica) - 15 (short form) contêm questões relacionadas à percepção do entrevistado sobre a própria vida, buscando informações sobre possível tendência depressiva. A pontuação se dá somando um ponto a cada resposta afirmativa para depressão. O participante foi excluído quando sua pontuação foi acima de 5 pontos, o que já indica início de depressão (FERRARI et al., 2007) (ANEXO D).

\subsubsection{Timed Up And Go Test}

O Timed Up and Go Test (TUG) consiste em um teste usado para verificar risco de quedas em idosos. Para executar esse teste o sujeito deve partir da posição sentada em uma cadeira, levantar-se, andar 3 metros, dar a volta em outra cadeira, voltar a sentar-se na cadeira inicial. O participante foi excluído nos casos de alto risco de quedas, ou seja, tempo de percurso acima de 20s. (PODSIADLO \& RICHARDSON, 1991) (ANEXO E).

\subsubsection{Escala de Equilíbrio de Berg}

A Escala de Equilíbrio de Berg (EEB), validada por Miyamoto et al. (2004) foi usado para determinar os fatores de risco para perda da independência e para quedas em idosos. Segundo Perracini e Flo (2009) a escala de equilíbrio de Berg é uma escala que atende várias propostas tais como a descrição quantitativa da habilidade de equilíbrio funcional, acompanhamento do progresso dos pacientes e avaliação da efetividade das intervenções na prática clínica e em pesquisas. A EEB avalia o desempenho do equilíbrio funcional em 14 itens comuns à vida diária. Cada item 
possui uma escala composta de cinco alternativas que variam de 0 a 4 pontos. Com a pontuação máxima podendo chegar a 56. Os pontos são baseados no tempo em que uma posição pode ser mantida, na distância em que o membro superior é capaz de alcançar à frente do corpo e no tempo para completar a tarefa. Para a realização da EEB são necessários: um relógio, uma régua, um banquinho e uma cadeira, e o tempo de execução é de aproximadamente 30 minutos. A EEB foi realizada com pacientes vestidos, descalços e fazendo uso de óculos e/ou próteses auditivas de uso habitual.

Foram excluídos da pesquisa os participante que tiveram a pontuação igual ou inferior a 45 pontos (THORBAHN; NEWTON, 1996) (ANEXO F).

\subsubsection{Health Assessment Questionnarie}

O Health Assessment Questionnarie (HAQ) é um instrumento avalia a capacidade dos pacientes realizarem tarefas usando para tanto duas a três questões em cada um dos oito domínios. Estes domínios abordam questões cotidianas como higiene pessoal, tarefas domésticas como aspirar, abrir torneiras e frascos, avaliando-os em uma escala de 0 (sem qualquer dificuldade), 1 (pouca dificuldade), 2 (muita dificuldade) e 3 (incapaz de realizar) sendo este o valor mais alto obtido em uma das perguntas de cada componente dos domínios citados. O índice é calculado pela média dos escores dos oito componentes. O teste foi validado por Ferraz et al. (1990) e escolhido para o estudo por poder ser utilizado fora do ambiente clínico, ter alta confiabilidade no teste e re-teste e grande utilização em pesquisas nacionais e internacionais que envolvem a temática da capacidade funcional segundo Paixão Jr e Reichenheim (2005). Foram excluídos da pesquisa participantes que a média final não ultrapassou 1 ponto (MOTA; LAURINDO; SANTOS NETO, 2010). Duração média da aplicação é de 10 minutos (ANEXO G).

\subsubsection{Teste de Romberg Clássico}

O teste de Romberg clássico foi usado para verificar se o indivíduo possui algum tipo de transtorno cerebelar e vestibular. Foi realizado com o participante em posição bipodal com calcanhares unidos e ponta dos pés separados em $30^{\circ}$. O paciente deveria ser capaz de manter-se com os olhos abertos, indica função cerebelar normal. O teste realizado com os olhos fechados indica complicações otoneurológicas. Duração de 1 min, sendo 30s com os olhos abertos e 30s com os olhos fechados. O 
teste é considerado positivo se houver um desequilíbrio que desencadeie queda, sendo assim o indivíduo será excluído do trabalho (MEDEIROS et al., 2007) (ANEXO H).

4.7.2 Descrição dos testes da fase de avaliação pré intervenção

Participaram da coleta de dados os sujeitos que passaram por todos os critérios de inclusão anteriormente citados. Foram realizados testes específicos para equilíbrio aplicados antes e após o protocolo de intervenção de posições de Yoga sobre com o Nintendo Wii Fit.

4.7.2.1 Teste de Romberg modificado sobre a Plataforma de Força-PF (dezesseis posições sensibilizadas)

Aplicação de um conjunto de teste com 16 posições sensibilizadas de Romberg descritos por Dorigueto et al. (2009). Este teste teve a função de verificar a oscilação do corpo durante 30 segundos de equilíbrio estático em uma plataforma de força (EMG system do Brasil) com e sem modificação da superfície com espuma de $10 \mathrm{~mm}$ de altura e densidade de 30g/dm³. Duração média de 25 minutos (ANEXO I).

\begin{tabular}{c|l}
\hline \multicolumn{1}{c|}{ Posicionamento } & \multicolumn{1}{c}{ Descrição } \\
\hline $1^{\mathrm{a}}$ a $4^{\mathrm{a}}$ posição & $\begin{array}{l}\text { O sujeito ficará com os pés separados confortavelmente } \\
\text { e orientado a manter-se o mais estável possível com os } \\
\text { olhos abertos e fechados em superfícies estáveis e } \\
\text { instáveis por 30 segundos. }\end{array}$ \\
\hline $5^{\mathrm{a}}$ a $8^{\mathrm{a}}$ posição) & $\begin{array}{l}\text { O sujeito posicionará o calcanhar do pé não } \\
\text { predominante ao lado do hálux do pé predominante. } \\
\text { Deverá permanecer com os olhos abertos e fechados } \\
\text { em superfície estável e instável por 30 segundos. }\end{array}$ \\
\hline $9^{\mathrm{a}}$ a $12^{\mathrm{a}}$ posição) & $\begin{array}{l}\text { Consiste em permanecer em apoio unipodal com o pé } \\
\text { direito com os olhos abertos e fechados sobre } \\
\text { superfícies estáveis e instáveis por 30 segundos. }\end{array}$ \\
\hline & $\begin{array}{l}\text { Consiste em permanecer em apoio unipodal com o pé } \\
\text { esquerdo com os olhos abertos e fechados sobre } \\
\text { superfícies estáveis e instáveis por 30 segundos. }\end{array}$ \\
\hline
\end{tabular}

Quadro 1 - Descrições de posições efetuadas no estudo 
7- Palm Tree

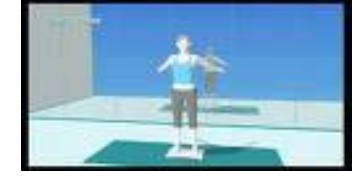

Posição bipodal com extensão de joelhos e hiperextensão de ombros com cotovelos estendidos. Faz-se uma flexão plantar mantendo o equilíbrio no antepé.

4.7.3 Fase de intervenção

A cada sessão foi aplicado um ckecklist (ANEXO J) com o objetivo de verificar possíveis variáveis detectadas no questionário inicial, como por exemplo, a não utilização de lentes corretoras da visão, a não ingestão de remédios prescritos, etc.

O protocolo de intervenção (ANEXO K), consistiu em executar 14 posturas de Yoga sobre a plataforma Wii Balance Board ilustradas no QUADRO 2. Em cada sessão as posições foram randomizadas a fim de evitar aprendizado da sequência estipulada.

Cada postura foi mantida pelo tempo pré-programado pelo software com duração média de 20 segundos de permanência.

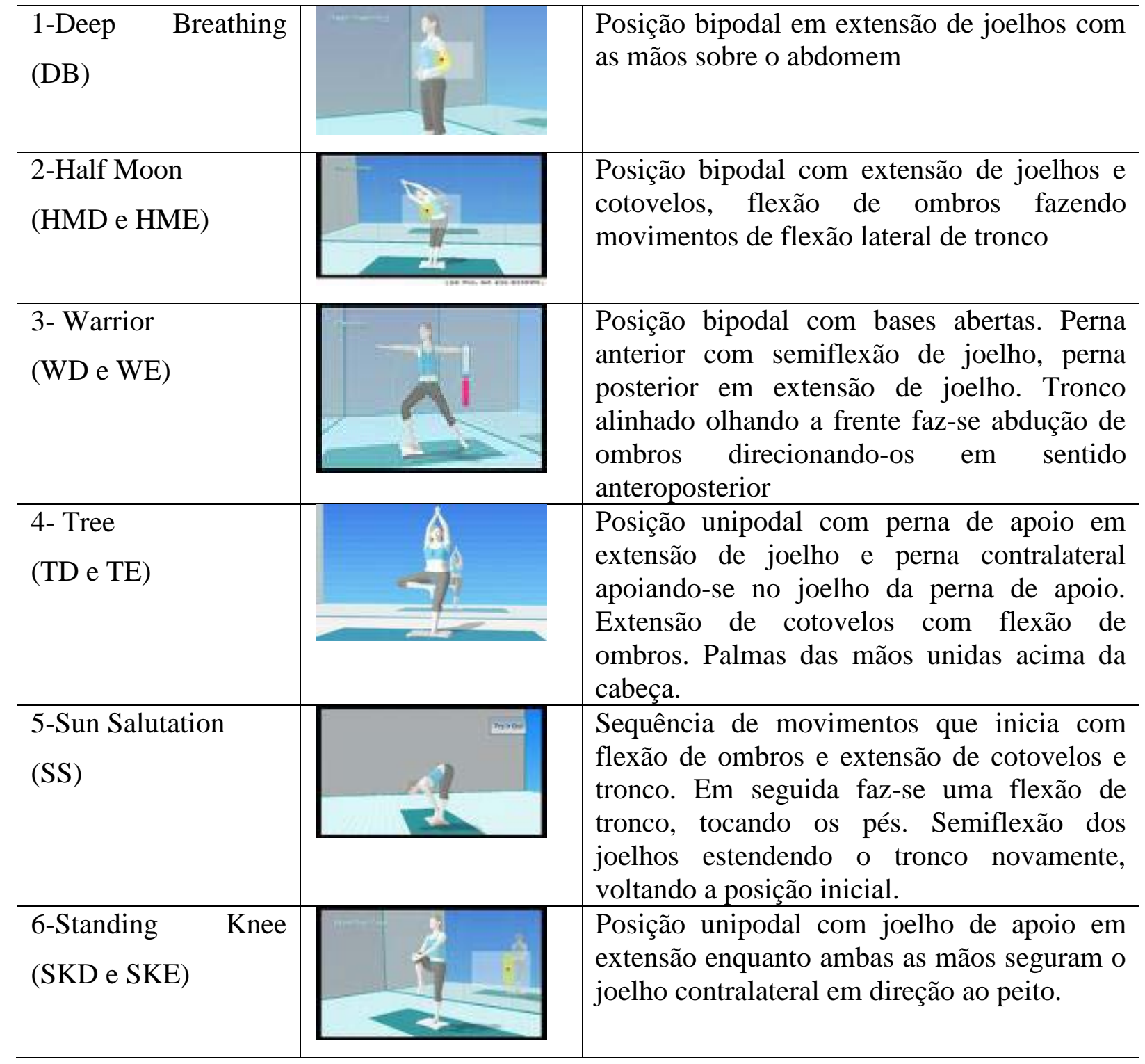




\begin{tabular}{|c|c|c|}
\hline 8- Chair (CH) & -4 & $\begin{array}{l}\text { Posição bipoal com semiflexão de joelhos e } \\
\text { flexão de } 90^{\circ} \text { de ombro com cotovelos } \\
\text { estendidos. Faz-se uma flexão plantar } \\
\text { mantendo o equilíbrio no antepé. }\end{array}$ \\
\hline $\begin{array}{l}\text { 9- Triangle } \\
\text { (TrD e TrE) }\end{array}$ & 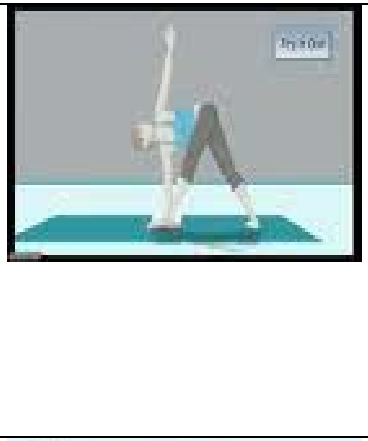 & $\begin{array}{l}\text { Posição bipodal com bases abertas. Perna } \\
\text { anterior com semiflexão de joelho, perna } \\
\text { posterior em extensão de joelho. Tronco } \\
\text { alinhado olhando a frente faz-se abdução de } \\
\text { ombros direcionando-os em sentido } \\
\text { anteroposterior Realiza-se uma torção de } \\
\text { tronco de modo que a mão posterior toque o } \\
\text { pé anterior, enquanto a mão anterior estende- } \\
\text { se em direção ao teto. }\end{array}$ \\
\hline 10- Dance (DD e DE) & 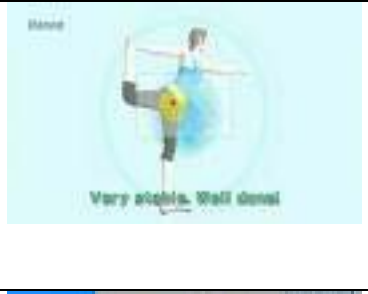 & $\begin{array}{l}\text { Posição unipodal com perna de apoio com } \\
\text { joelho em extensão e perna contralateral em } \\
\text { hiperextensão de modo que o pé é mantido } \\
\text { em contato com a mão homolateral. Braço } \\
\text { contralateral à perna de apoio fica em flexão } \\
\text { de } 90^{\circ} \text { e extensão de cotovelo. }\end{array}$ \\
\hline $\begin{array}{l}\text { 11- Downward- } \\
\text { facing Dog } \\
\text { (DFD) }\end{array}$ & & $\begin{array}{l}\text { Posição inicial em } 4 \text { apoios (decúbito } \\
\text { ventral) com cotovelos estendidos, lançar o } \\
\text { cóccix ao alto em direção ao teto com uma } \\
\text { extensão de joelhos segurando a posição com } \\
\text { a direção do olhar voltada ao abdomem }\end{array}$ \\
\hline $\begin{array}{l}\text { 12- Spine Extension } \\
\text { (SED e SEE) }\end{array}$ & & $\begin{array}{l}\text { Posição bipodal bases abertas em sentido } \\
\text { anteroposterior com os joelhos estendidos, } \\
\text { uni-se as palmas das mãos na parte posterior } \\
\text { do tronco fazendo uma flexão anterior de } \\
\text { tronco. }\end{array}$ \\
\hline $\begin{array}{l}\text { 13- Gate } \\
\text { (GD e GE) }\end{array}$ & & $\begin{array}{l}\text { Posição semi-ajoelhada com um membro } \\
\text { inferior em apoio ajoelhado e o outro } \\
\text { membro em abdução com extensão de } \\
\text { joelho. Faz-se então flexão lateral de tronco } \\
\text { para o lado do membro inferior em abdução, } \\
\text { com o braço contralateral em flexão de } \\
\text { ombro e extensão de cotovelo acima da } \\
\text { cabeça, enquanto o braço do lado da perna } \\
\text { em extensão tenta alcançar o pé. }\end{array}$ \\
\hline $\begin{array}{ll}\text { 14- } & \text { Grounded } V \\
(\mathrm{GV}) & \end{array}$ & & $\begin{array}{l}\text { Posição sentada sobre o wii balance board } \\
\text { com apoio dos braços posteriormente } \\
\text { elevam-se os membros inferiores com os } \\
\text { joelhos em extensão de modo a formar um } \\
\text { grande V com o corpo. }\end{array}$ \\
\hline
\end{tabular}

Quadro 2 - Posturas de Yoga segundo a sequência pré programada pelo Nintendo Wii com as siglas de identificação das posições. 
O protocolo de intervenção foi realizado da seguinte forma: 3 sessões semanais, com cerca de 30 minutos de duração, ao longo de 8 semanas, gerando um total de 24 sessões ou $8 \mathrm{~h}$ contínuas de atividades. Estas ocorreram em uma sala previamente preparada no ECEU/USP.

\subsubsection{Fase pós-intervenção}

1- Teste de Romberg modificado na Plataforma de Força- PF (dezesseis posições sensibilizadas)

2- Escala de Equilíbrio de Berg

3- Timed Up And Go Test

4- Questionário aberto sobre a satisfação do paciente com a intervenção além de uma escala quantitativa de 0 a 10 sobre a percepção do equilíbrio postural após intervenção. Duração da aplicação de 1 min. (ANEXO L).

Medida de prevenção de riscos e desconfortos

Os procedimentos não apresentaram desconfortos e riscos aos sujeitos. Os testes de equilíbrio apresentaram baixo risco de quedas, entretanto, estes foram assistidos pelo pesquisador que se posicionou ao lado do sujeito evitando que o mesmo sofresse queda.

Controle de variáveis de interferência

Durante o processo de aplicação do protocolo de intervenção, foi feita uma lista de checagem (checklist) verificando possíveis mudanças entre as condições anteriormente relatadas e as atuais tais como o uso ou não dos dispositivos de auxílio à função (óculos, bengalas, órteses) relatada no questionário inicial; uso de medicamentos e alimentação adequada, sono e demais alterações que pudessem interferir nos resultados. A pressão arterial foi aferida em todas as sessões. O voluntário apenas iniciou as atividades quando todos os requisitos do checklist foram satisfatórios. 
4.8 Análise de dados

Foram coletados dados a partir de uma Plataforma de Força que consiste em uma placa sob a qual alguns (tipicamente quatro) sensores de forca do tipo célula de carga ou piezelétrico estão arranjados para medir os três componentes da forca, Fx, Fy e Fz (x, y e z são as direções ântero-posteriores (AP), mediolateral (ML) e vertical, respectivamente), e os três componentes do momento de forca (ou torque), $\mathrm{Mx}$, My e Mz, agindo sobre a plataforma. O programa MatLab 7.4.0 (R2007a) foi utilizado para aquisição de processamento do sinal da plataforma.

A medida posturográfica mais comumente utilizada na avaliação do controle postural é o Centro de Pressão (CP). O CP é o ponto de aplicação da resultante das forcas verticais agindo sobre a superfície de suporte. Os dados do CP adquiridos podem ser visualizados de duas formas: por um estatocinesigrama ou por um estabilograma. O estatocinesigrama (Figura 1) é o mapa do CP na direção AP versus o CP na direção ML, enquanto o estabilograma (Figura 2) é a série temporal do CP em cada uma das direções: AP e ML.

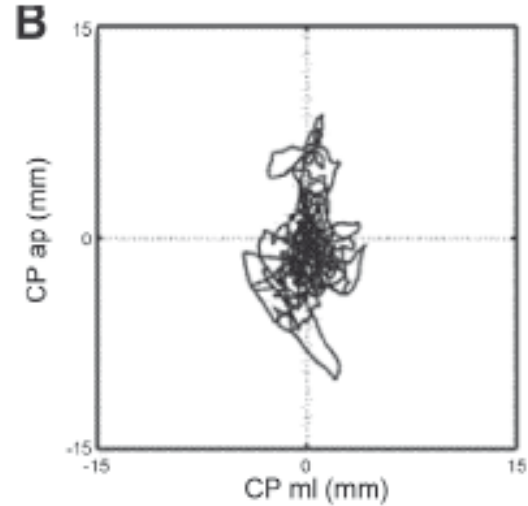

Figura 2 - Representação de um Estatocinesigrama

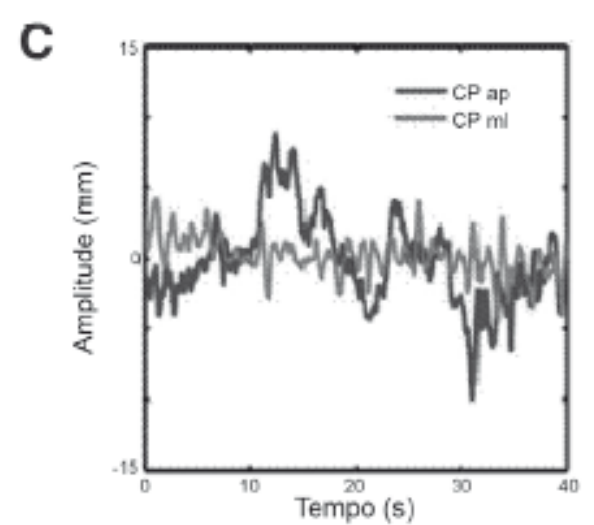

Figura 3 - Representação de um Estabilograma

Após o processamento dos sinais da plataforma foi selecionado dentre as diversas variáveis apresentadas para cada postura, algumas que conseguissem demonstrar o desempenho dos sujeitos durante as avaliações. Para tanto, foram destacadas as seguintes variáveis: amplitudes AP e ML que representam a distância entre o deslocamento máximo e mínimo do CP para cada direção; os desvios padrão AP e ML que apontam a dispersão do deslocamento do CP da posição média durante um intervalo de tempo; a velocidade AP e ML que indicam a velocidade com que ocorreram as oscilações; área de deslocamento que 
determina o espaço percorrido pelo CP durante o tempo de aquisição do sinal em cada uma das 14 posições sobre a plataforma nos momentos pré e pós intervenção.

\subsubsection{Análise Estatística}

Foi realizada uma análise exploratória de dados através de gráficos e de medidas de resumo (média, desvio-padrão, mediana, valor mínimo e máximo, coeficiente de variação e intervalo de confiança 95\% para a média).

As comparações foram feitas através de contrastes ortogonais utilizando o modelo linear de efeitos mistos (efeitos aleatórios e fixos). Este modelo é utilizado na análise de dados onde as respostas de um mesmo indivíduo estão agrupadas e a suposição de independência entre as observações num mesmo grupo não é adequada (SCHALL, 1991). Para a utilização deste modelo, é preciso que seus resíduos tenham distribuição normal com média zero e variância constante. O ajuste do modelo foi feito através do procedimento PROC MIXED do software SAS $^{\circledR} 9.1$. 


\section{RESULTADOS}

5.1 Dados de caracterização dos sujeitos

A população do estudo foi composta por 6 mulheres com média de idade de 67,6 anos, sendo que quatro delas moram com a família e dois moram sozinhas. Destas, 5 estão aposentadas e uma atua no setor administrativo como funcionária pública. Quanto à escolaridade, 2 possuem o ensino fundamental, 3 o ensino médio e 1 o ensino superior.

\begin{tabular}{c|c}
\hline Descritores & (n) \\
\hline Diagnósticos Referidos & 4 \\
-Circulatório & 1 \\
-Osteomuscular & 3 \\
-Endócrinos & \\
\hline Medicação e Suplementos & 4 \\
-Anti-hipertensivo & 1 \\
-Reposição de Cálcio & 3 \\
-Regulador hormonal & \\
\hline Problema visual & 5 \\
SIM & 1 \\
NÃO & 1 \\
\hline Problemas auditivos & 5 \\
SIM & \\
NÃO & 5 \\
SIM & 1 \\
NÃO & 3 \\
\hline Modalidade & 3 \\
-Caminhada & 1 \\
-Exercícios resistidos & 3 \\
\hline Freqüência & 1 \\
1x/semana & \\
2x/semana & \\
5x/semana & \\
\hline Tempo que pratica & \\
Mais de 6 meses & \\
Mais de 1 ano & \\
\hline
\end{tabular}

Quadro 3 - Caracterização dos sujeitos quanto às complicações de saúde e características das práticas físicas. 


\begin{tabular}{l|c|c}
\hline \multicolumn{1}{c|}{ Teste } & (n) & $\begin{array}{c}\text { Pontuação } \\
\text { média/Resultado }\end{array}$ \\
\hline Tontura Relatada (DHI) & 1 & (26) Tontura leve \\
\hline Capacidade Funcional (HAQ) & 6 & $(0,41)$ Independente \\
\hline Índice de Massa Corporal (IMC) & 6 & $(24,50)$ Peso normal \\
\hline
\end{tabular}

Quadro 4 - Caracterização dos sujeitos quanto à capacidade funcional e Índice de Massa Corporal (IMC).

Os dados obtidos estão apresentados sobre cinco aspectos: o primeiro é decorrente da pontuação fornecida pelo Nintendo Wii durante as 24 sessões de intervenção para as 14 posturas de Yoga (Tabela 1); o segundo apresenta as pontuações obtidas com a plataforma de força nas 14 posições modificadas e sensibilizadas da posição original de Romberg (Tabela 2); o terceiro apresenta os tempos percorridos durante o Timed Up And Go Test (Tabela 3); o quarto apresenta os valores obtidos na Escala de Equilíbrio de Berg (Tabela 4) e o quinto apresenta os resultados quanto à satisfação dos sujeitos com a utilização do Nintendo Wii Fit Yoga (Tabela 5).

\subsection{Dados obtidos com o Nintendo Wii}

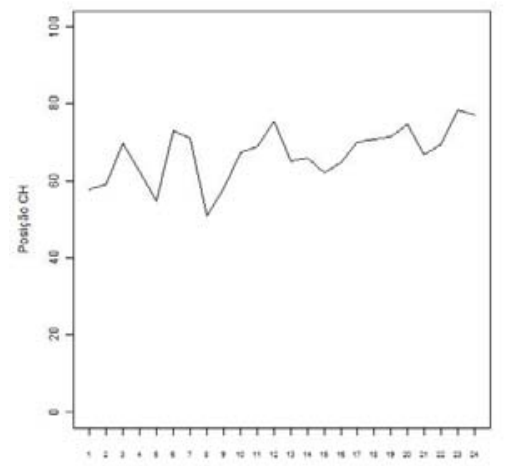

Sess3o

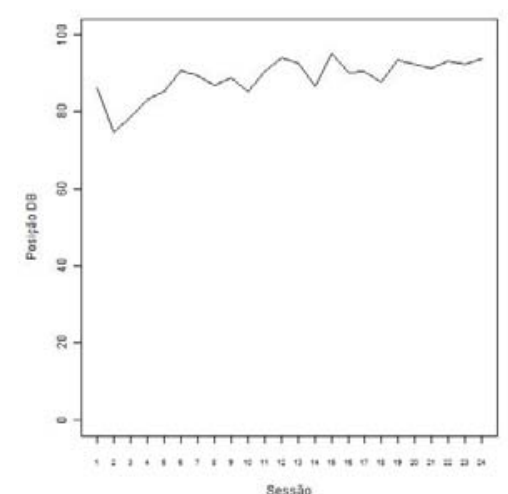

sess.30

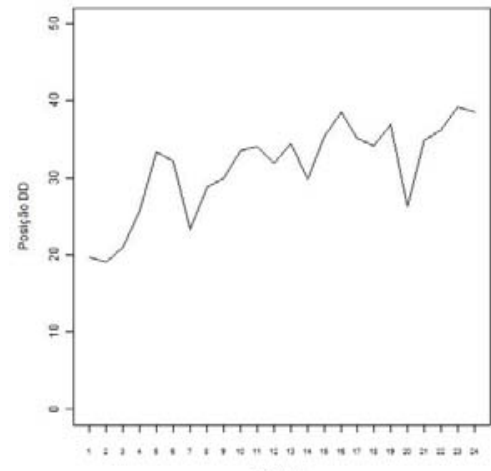

Sessaso

Gráfico 1 - Pontuações obtidas pelos participantes em cada uma das 14 posições de Yoga fornecidas pelo Nintendo Wii Fit. (continua) 

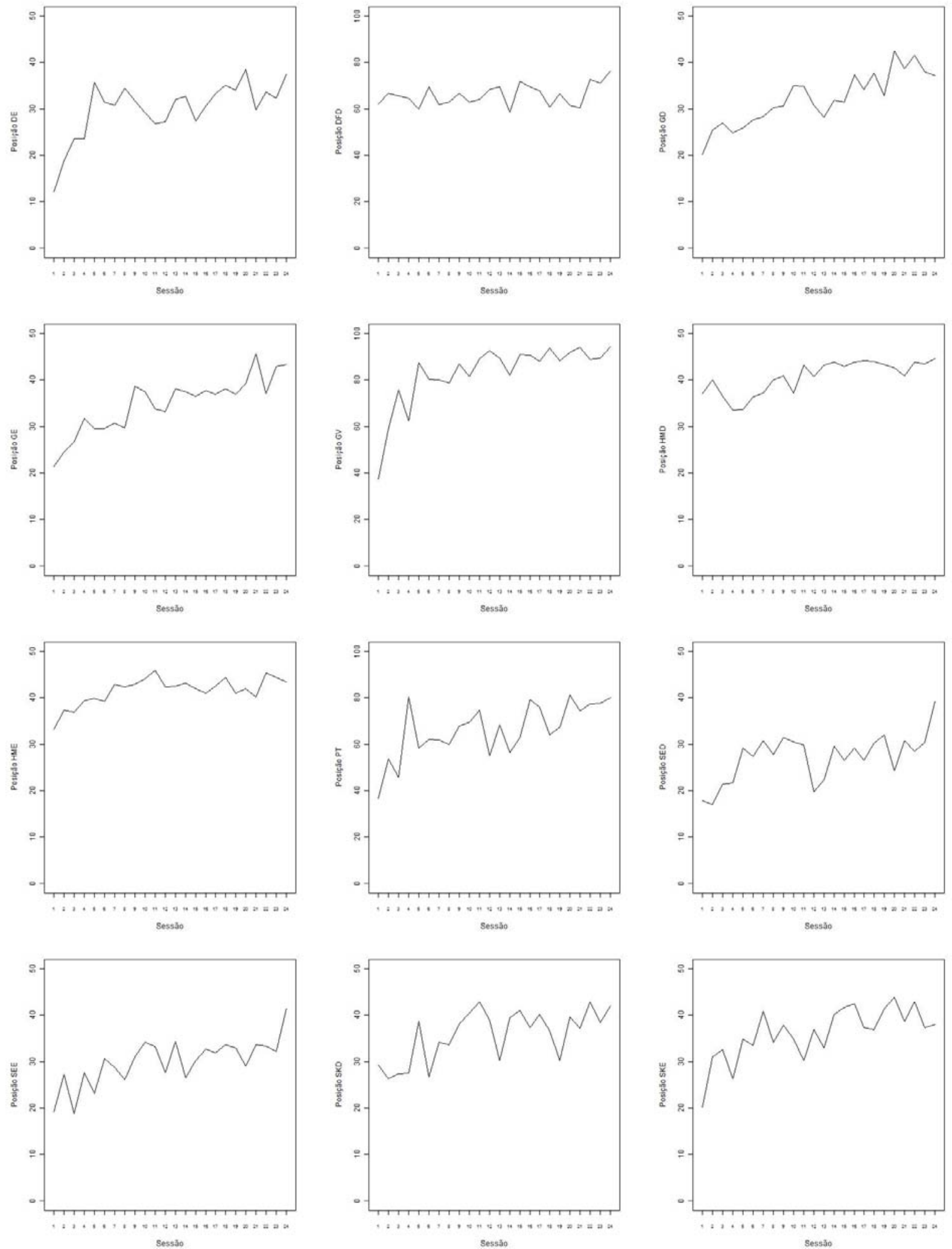

Gráfico 1 - Pontuações obtidas pelos participantes em cada uma das 14 posições de Yoga fornecidas pelo Nintendo Wii Fit. (continuação) 

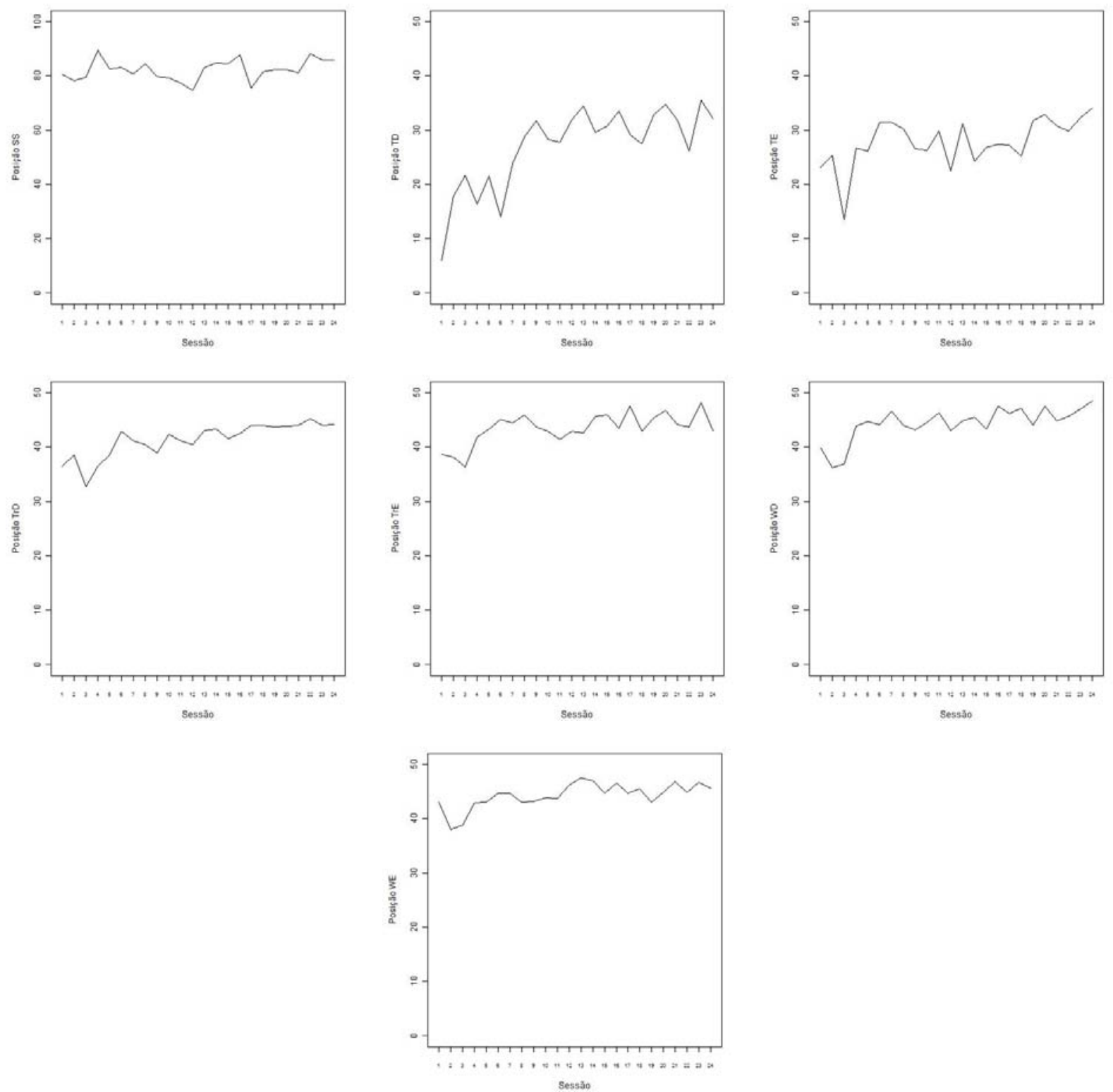

Gráfico 1 - Pontuações obtidas pelos participantes em cada uma das 14 posições de Yoga fornecidas pelo Nintendo Wii Fit. (conclusão)

Observação: Estão sendo apresentados 22 gráficos, relativos a 14 posições, porém existem posições que são executadas com o lado direito e esquerdo.

Tabela 1 - Dados da média e desvio padrão dos 6 participante na $2^{\mathrm{a}}$, $12^{\mathrm{a}}$ e $24^{\mathrm{a}}$ sessão.

\begin{tabular}{lrrr}
\hline Posições & \multicolumn{1}{c}{$\mathbf{2}^{\text {a }}$ Sessão } & \multicolumn{1}{c}{ 12 $^{\text {a }}$ Sessão } & \multicolumn{1}{c}{ 24 $^{\text {a }}$ Sessão } \\
\hline DB & $59 \pm 21,86$ & $75,33 \pm 4,84$ & $77 \pm 4,86$ \\
HMD & $40 \pm 5,69$ & $40,67 \pm 5,35$ & $44,5 \pm 1,52$ \\
HME & $37,33 \pm 4,8$ & $42,33 \pm 3,98$ & $43,5 \pm 4,46$ \\
WD & $36,17 \pm 10,72$ & $43 \pm 6,87$ & $48,5 \pm 1,38$ \\
WE & $38 \pm 5,69$ & $46,17 \pm 3,66$ & $45,67 \pm 4,68$ \\
& & & (continua)
\end{tabular}


Tabela 1 - Dados da média e desvio padrão dos 6 participante na $2^{\mathrm{a}}$, $12^{\mathrm{a}}$ e $24^{\mathrm{a}}$ sessão. (conclusão)

\begin{tabular}{lrrr}
\hline Posições & \multicolumn{1}{c}{ 2 Sessão } & \multicolumn{1}{c}{$\mathbf{1 2}^{\text {a }}$ Sessão } & \multicolumn{1}{c}{$\mathbf{2 4}^{\text {a }}$ Sessão } \\
\hline TD & $17,83 \pm 15,22$ & $31,83 \pm 7,05$ & $32,17 \pm 7,78$ \\
TE & $25,33 \pm 8,14$ & $22,5 \pm 14,47$ & $34 \pm 8,34$ \\
SS & $78,17 \pm 11,27$ & $74,5 \pm 29,92$ & $85,83 \pm 7,94$ \\
SKD & $26,33 \pm 16,54$ & $39 \pm 6,75$ & $42 \pm 3,35$ \\
SKE & $31 \pm 16,31$ & $36,83 \pm 13,64$ & $38 \pm 9,19$ \\
PT & $53,67 \pm 17,64$ & $55 \pm 29,31$ & $80 \pm 3,35$ \\
CH & $59 \pm 21,86$ & $75,33 \pm 4,84$ & $77 \pm 4,86$ \\
TrD & $38,5 \pm 7,77$ & $40,5 \pm 9,61$ & $44,17 \pm 6,55$ \\
TrE & $38,17 \pm 5,85$ & $42,83 \pm 7,63$ & $43 \pm 4,2$ \\
DFD & $66,83 \pm 10,42$ & $68,33 \pm 6,56$ & $76,17 \pm 13,39$ \\
DD & $19 \pm 19,18$ & $31,83 \pm 16,41$ & $38,5 \pm 5,24$ \\
DE & $18,83 \pm 18,03$ & $27,17 \pm 15,73$ & $37,5 \pm 3,62$ \\
SED & $17 \pm 20,73$ & $19,67 \pm 14,28$ & $39,17 \pm 11,63$ \\
SEE & $27,17 \pm 16,96$ & $27,67 \pm 13,88$ & $41,33 \pm 4,97$ \\
GD & $25,5 \pm 14,65$ & $30,83 \pm 14,47$ & $37,17 \pm 10,83$ \\
GE & $24,5 \pm 16,02$ & $33,17 \pm 8,66$ & $43,33 \pm 3,93$ \\
GV & $59 \pm 32,74$ & $92,67 \pm 5,47$ & $94,33 \pm 8,98$ \\
\hline
\end{tabular}


5.3 Dados da plataforma de força

Tabela 2 - Comparações entre pré e pós intervenção na plataforma de força.

\begin{tabular}{|c|c|c|c|c|}
\hline Variáveis & Posição & Valor pré & Valor pós & Valor de $p$ \\
\hline \multirow{10}{*}{ Amplitude AP } & 1 & 1,15 & 1,05 & 0,86 \\
\hline & 2 & 1,37 & 1,7 & 0,59 \\
\hline & 3 & 1,6 & 1,23 & 0,54 \\
\hline & 4 & 1,54 & 1,65 & 0,85 \\
\hline & 5 & 1,53 & 1,24 & 0,59 \\
\hline & 6 & 1,77 & 2,07 & 0,62 \\
\hline & 7 & 2,29 & 1,52 & 0,20 \\
\hline & 8 & 2,44 & 2,23 & 0,72 \\
\hline & 9 & 3,61 & 2,57 & 0,11 \\
\hline & 10 & 3,64 & 3,62 & 0,61 \\
\hline \multirow{10}{*}{ Amplitude ML } & 1 & 0,67 & 0,66 & 0,99 \\
\hline & 2 & 0,87 & 0,83 & 0,95 \\
\hline & 3 & 1,0 & 0,6 & 0,52 \\
\hline & 4 & 0,74 & 0,85 & 0,85 \\
\hline & 5 & 1,85 & 1,60 & 0,69 \\
\hline & 6 & 2,39 & 2,04 & 0,58 \\
\hline & 7 & 3,03 & 2,57 & 0,46 \\
\hline & 8 & 3,25 & 2,51 & 0,23 \\
\hline & 9 & 2,76 & 2,35 & 0,52 \\
\hline & 10 & 2,91 & 2,48 & 0,40 \\
\hline \multirow{10}{*}{ Desvio AP } & 1 & 0,22 & 0,22 & 0,99 \\
\hline & 2 & 0,30 & 0,35 & 0,99 \\
\hline & 3 & 0,27 & 0,23 & 0,95 \\
\hline & 4 & 0,29 & 0,32 & 0,99 \\
\hline & 5 & 0,30 & 0,23 & 0,92 \\
\hline & 6 & 0,31 & 0,45 & 0,95 \\
\hline & 7 & 0,37 & 0,29 & 0,90 \\
\hline & 8 & 0,42 & 0,41 & 0,92 \\
\hline & 9 & 0,61 & 0,47 & 0,79 \\
\hline & 10 & 0,64 & 0,63 & 0,91 \\
\hline \multirow{10}{*}{ Desvio ML } & 1 & 0,13 & 0,11 & 0,99 \\
\hline & 2 & 0,16 & 0,25 & 0,64 \\
\hline & 3 & 0,18 & 0,10 & 0,74 \\
\hline & 4 & 0,15 & 0,17 & 0,81 \\
\hline & 5 & 0,36 & 0,33 & 0,53 \\
\hline & 6 & 0,42 & 0,37 & 0,20 \\
\hline & 7 & 0,55 & 0,49 & 0,47 \\
\hline & 8 & 0,57 & 0,48 & 0,91 \\
\hline & 9 & 0,55 & 0,45 & 0,25 \\
\hline & 10 & 0,57 & 0,47 & 0,67 \\
\hline
\end{tabular}


Tabela 2 - Comparações entre pré e pós intervenção na plataforma de força. (conclusão)

\begin{tabular}{ccrrr}
\hline Variáveis & Posição & Valor pré & Valor pós & Valor de p \\
\hline \multirow{4}{*}{ Velocidade AP } & 1 & 0,74 & 0,54 & 0,94 \\
& 2 & 0,80 & 0,60 & 0,61 \\
& 3 & 1,0 & 0,76 & 0,66 \\
& 4 & 0,93 & 0,87 & 0,90 \\
& 5 & 1,06 & 0,81 & 0,86 \\
Velocidade ML & 1,11 & 0,86 & 0,76 \\
& 7 & 1,64 & 1,34 & 0,74 \\
& 8 & 1,71 & 1,40 & 0,62 \\
& 9 & 2,44 & 1,92 & 0,60 \\
& 10 & 2,37 & 2,39 & 0,56 \\
\hline & 1 & 0,45 & 0,42 & 0,64 \\
& 2 & 0,47 & 0,45 & 0,64 \\
& 3 & 0,52 & 0,50 & 0,58 \\
& 4 & 0,50 & 0,53 & 0,90 \\
& 6 & 1,05 & 0,93 & 0,57 \\
& 7 & 1,23 & 1,07 & 0,55 \\
& 8 & 1,94 & 1,69 & 0,47 \\
& 9 & 2,03 & 2,0 & 0,46 \\
& 10 & 2,95 & 2,74 & 0,32 \\
& 1 & 2,84 & 2,86 & 0,64 \\
\hline & 0,54 & 0,46 & 0,95 \\
& 9 & 0,90 & 0,94 & 0,96 \\
& 3 & 1,05 & 0,42 & 0,96 \\
& 4 & 0,92 & 1,03 & 0,95 \\
& 5 & 2,32 & 1,34 & 0,79 \\
& 6 & 2,58 & 3,18 & 0,71 \\
& & 3,67 & 2,45 & 0,57 \\
& 4,28 & 3,35 & 0,95 \\
& 6,92 & 4,02 & 0,67 \\
& 6,90 & 5,61 & 0,66 \\
\hline
\end{tabular}


5.4 Dados do Timed Up and Go Test (TUG)

Tabela 3 - Resultados do TUG.

\begin{tabular}{|c|c|c|c|c|c|c|c|c|c|c|}
\hline \multirow{2}{*}{ Avaliação } & \multirow{2}{*}{ Variável } & \multirow{2}{*}{ N. } & \multirow{2}{*}{ Média } & \multirow{2}{*}{ Desvio Padrão } & \multirow{2}{*}{ Mínimo } & \multirow{2}{*}{ Mediana } & \multirow{2}{*}{ Máximo } & \multirow{2}{*}{ Coef. Var. } & \multicolumn{2}{|c|}{ IC 95\% } \\
\hline & & & & & & & & & LI & LS \\
\hline \multirow{2}{*}{ Pós Intervenção } & tempo & 6 & 9,03 & 0,9 & 8,29 & 8,81 & 10,72 & 10,01 & 8,08 & 9,97 \\
\hline & passos & 6 & 16 & 0,63 & 15 & 16 & 17 & 3,95 & 15,34 & 16,66 \\
\hline \multirow{2}{*}{ Pré Intervenção } & tempo & 6 & 11,2 & 1,7 & 9,56 & 11,09 & 14,14 & 15,14 & 9,42 & 12,98 \\
\hline & passos & 6 & 17 & 1,1 & 16 & 17 & 19 & 6,44 & 15,85 & 18,15 \\
\hline
\end{tabular}

5.5 Dados da Escala de Equilíbrio de Berg (EEB)

Para a realização da análise dos dados, a EEB foi dividida em grupos com tarefas funcionais semelhantes: transferências (questões 1, 4 e 5), provas estacionárias (questões 2, 3, 6 e 7), alcance funcional (questão 8), componentes rotacionais (questões 9, 10 e 11) e base de sustentação diminuída (questões 12, 13 e 14) (FRANCIULLI et al., 2007).

Em relação aos dados da EEB foram constatados aumentos em todos os 6 casos analisados. Veja tabela abaixo com os dados:

Tabela 4 - Média da pontuação de Berg em cada um dos grupos de tarefas.

\begin{tabular}{lrr} 
Grupo de tarefas de Berg & Pré intervenção & Pós intervenção \\
\hline Berg (pontuação total) & 52,5 & 54,6 \\
Transferências & 10,8 & 11,8 \\
Provas estacionárias & 15,8 & 16 \\
Alcance funcional & 3,8 & 4 \\
Componentes rotacionais & 11 & 11,8 \\
Base de sustentação & 11,5 & 12
\end{tabular}

Nota: Tabela com os dados de cada indivíduo estão apresentados no ANEXO M. 


\section{DISCUSSÃO}

As novas tecnologias têm sido incorporadas aos diferentes contextos de tratamento tanto voltados para o sujeito idoso como para as populações com disfunções motoras. Estas atualmente têm caráter complementar às terapias convencionais e podem otimizar o trabalho de reabilitação com sujeitos com disfunções físicas ou serem utilizadas como ferramenta para a promoção de saúde.

\subsection{Discussão sobre o protocolo de seguimento proposto}

Diversos aspectos devem ser ressaltados na avaliação do protocolo de seguimento proposto com o Nintendo Wii. O primeiro se refere à dificuldade de se fazer uma pesquisa longitudinal e manter a adesão dos sujeitos durante todo o protocolo. Vários seguimentos foram iniciados e interrompidos por demandas espontâneas dos idosos. Estas demandas se relacionavam principalmente com os papéis ocupacionais desenvolvidos como tomar conta dos netos e com as viagens do que por motivo de doença. $\mathrm{O}$ fato dos sujeitos serem ativos e desenvolveram uma variada gama de atividades educativas, culturais, recreativas e físicas fazia com que a pesquisa disputasse um espaço nas agendas deles. Assim, o caráter longitudinal do estudo com a coleta de dados individualizada demandou grande período de tempo e consequentemente teve perda por desistência de alguns participantes ao longo do seguimento.

Sugere-se que estudos de intervenção tenham sujeitos controles como parâmetro comparativo, e as dificuldades no gerenciamento do tempo da pesquisa e na organização das múltiplas atividades do pesquisador combinada com a dificuldade na adesão dos sujeitos culminou com a perda dos sujeitos controles e consequentemente com a necessidade de comparar o sujeito com ele mesmo, tendo a intervenção com o Nintendo Wii como demarcador do antes e depois.

Este estudo teve caráter exploratório e não foi encontrado na literatura pesquisa semelhante com o desenho metodológico proposto. Eram variadas as composições de tempo de seguimento, freqüência, duração das sessões, jogos utilizados e características dos sujeitos participantes. Segundo alguns autores, uma intervenção que consistisse de um seguimento de 2 a 3 vezes por semana, de intensidade moderada a partir de um período de 2 meses já teríamos como mensurar resultados relevantes no que diz respeito aos testes aplicados, como o EEB e o TUG. Por essa razão supõe-se que o protocolo desenhado foi correto e segue de 
acordo com o que se tem proposto na literatura. (RUNGE; REHFELD; RESNICEK (2000); GIL-GOMEZ et al. (2011); MOUWAD et al. (2011); NITZ et al. (2010).

Do ponto de vista da combinação de testes avaliativos do equilíbrio e da capacidade funcional, estes foram escolhidos por serem os mais utilizados em pesquisas sobre o equilíbrio e bem avaliados quanto à confiabilidade e sensibilidade. Consideramos que houve sensibilidade na detecção de alterações do equilíbrio de idosos, levando-se em consideração que a população era ativa e praticante de atividade física.

\subsection{Discussão sobre os efeitos da prática com o Nintendo Wii Fit.}

A análise dos efeitos da prática virtual de Yoga sobre o controle postural de idosas ativas utilizando o Nintendo Wii deve ser feita sob diferentes pontos de vista. O primeiro se refere à avaliação quantitativa que permite mensurar os efeitos sobre o equilíbrio postural do idoso após o período de intervenção, expressos pelos dados da EEB, TUG, PF. Outro aspecto se refere à percepção de melhora do sujeito e a satisfação obtida com a intervenção feita.

Foi observada uma melhora no controle postural na realização das tarefas motoras funcionais propostas pela EEB. A pontuação média relativa às tarefas de transferências (questões 1, 4 e 5) apresentou um aumento de 0,8; nas provas estacionárias (questões 2, 3, 6 e 7) o aumento foi de 0,2, e no alcance funcional (questão 8) aumento de 0,2, nos componentes rotacionais (questões 9, 10 e 11) aumento 0,8 e nas tarefas de diminuição da base de sustentação (questões 12, 13 e 14) o aumento foi de 0,5. Como a tendência ascendente dos escores na contagem da EEB é avaliada positivamente, sugere-se que houve uma discreta melhora nos dados dos sujeitos.

Foi encontrado resultado negativo parecidos por Silva et al (2008) que verificaram que , após protocolo de intervenção com 61 idosos "bem sucedidos” (como consta no estudo) que receberam exercícios resistidos 3 vezes por semana durante 24 semanas, não houve diferença estatística significativa entre os grupos experimentais de idosos ou controle no que diz respeito aos dados da EEB. Sugere-se que testes confiáveis como a EEB amplamente utilizado na literatura podem não apontar mudanças estatísticas quando aplicados em indivíduos ativos.

Por outro lado Resende et al (2008) verificaram que após 12 semanas de intervenção com 25 idosas, que não participavam de outro tipo de assistência física, submetidas a um protocolo de exercícios de baixa e moderada intensidade de hidroterapia foi suficiente para que encontrasse melhora estatisticamente significativa quando avaliadas pela EEB. Com isso entendemos que a terapia teve um efeito importante na condição de controle 
do equilíbrio em pessoas com risco de quedas, contudo parece que o estado inicial do sujeito interfere diretamente no resultado inicial dos testes, podendo ter sido o fator que predispôs uns grupos terem tido melhora estatística enquanto outros não. Estudos semelhantes foram realizados Aguiar et al., (2008).

Quanto ao tempo de percurso medido pelo TUG, percebe-se uma diminuição deste no período de pós-intervenção. A pontuação média obtida foi de 11,2 segundos e 17 passos na avaliação de pré intervenção, e 9,03 segundos e 16 passos na avaliação pós intervenção. Assim, considera-se que houve um aumento da capacidade de execução da tarefa sugerindo que o controle do equilíbrio dinâmico foi alterado positivamente no reteste, assim como a amplitude de movimento das passadas. Estudo como o de Zambaldi et al.(2007) encontraram resultados semelhantes em suas amostras corroborando os resultados do estudo desenvolvido pelo pesquisador.

Em relação ao controle postural avaliado na PF, observa-se que não houve uma homogeneidade nas alterações dos dados das variáveis avaliadas. As diferenças entre o pré e o pós foram discretas e estatisticamente não significativas, não configurando uma convergência de melhora ou piora na execução das posições. No entanto, ressaltamos que as posições avaliadas têm graus de complexidade de execução diferentes. Aparentemente, conforme aumenta a complexidade das posições, há também uma maior tendência do valor de pós intervenção ser menor do que o valor da pré, sugerindo uma melhora na execução e consequentemente no controle postural das tarefas que compreendiam um maior desafio de execução.

Podemos ressaltar a eficácia na realização das posições 9, 10, 11, 12, 13 e 14 durante os 30 segundos de permanência que anteriormente não eram concluídas na fase de avaliação pré intervenção, por isso pode-se observar $\underline{\mathrm{N}}$ diferentes na apresentação do anexo N. Contudo os resultados foram inexpressivos quando submetidos à analise estatística, uma vez que em nenhuma das variáveis foi encontrado valor de $\mathrm{P}<0,05$.

\subsection{Discussão quanto a análise do questionário de satisfação}

No âmbito da análise qualitativa sobre da percepção em relação à melhora com a intervenção, as participantes referem ter ficado plenamente satisfeitas, pois identificaram que esta prática promoveu vários benefícios. Elas apontam terem tido melhora na sensação de dor no tornozelo e nas pernas, nas câimbras, no alongamento e na postura, na sensação de estabilidade e leveza do corpo. De acordo com Yeng et al. (2001) o relaxamento de estruturas tensas ou com contraturas podem ser aliviadas pelos exercícios isométricos, ativos livres e 
contra-resistidos. As atividades atuam na redução do edema e da inflamação, melhoram as condições circulatórias, aceleram o processo cicatricial e o relaxamento muscular, reduzem a dor e a incapacidade funcional e tais aspectos exercem influência também sobre a sensação de bem estar.

Quanto à opinião se se submeteriam a uma prática de atividade física com o Nintendo Wii, estas responderam positivamente e mencionaram que poderiam aprimorar os benefícios já alcançados com a intervenção e fazer mais naturalmente as posições propostas pelo Yoga.

6.4 Discussão sobre a sensibilidade do software frente à variação de desempenho do sujeito no decorrer da prática

Foi observado um aumento na pontuação gerada pelo software do game quando comparado às pontuações das primeiras e últimas sessões. Sugere-se que quanto mais desafiadora é a posição mais clara é a melhora do sujeito ao longo do período de intervenção. Com tendência a uma melhora na performance conforme a prática. Nas posições de menor complexidade, o sujeito tende a estabilizar a performance e consequentemente a pontuação obtida no jogo.

Sendo assim, a curva gerada pelo desempenho do grupo ao longo do tempo de intervenção sugere que o software foi sensível na captação da melhora dos componentes do equilíbrio exigidos pelo game.

Em primeira instância, os dados gerados pelo Nintendo Wii e pela PF são distintos e não passíveis de comparação. Embora, o Wii balance board funcione com um mecanismo semelhante ao de uma $\mathrm{PF}$, inclusive gerando um gráfico de deslocamento similar ao estatocinesigrama. Os dados gerados pelo Nintendo Wii e pela PF convergem para a melhora do controle postural dos sujeitos.

Pagnacco et al (2011) discutem sobre o fato das ciências biomédicas dependerem fortemente de dispositivos para adquirir e analisar os dados fisiológicos necessários para compreender e modelar os processos biológicos dos seres humanos e animais. Assim, os resultados das investigações, clínicos ou acadêmicos, dependem muito da instrumentação utilizada. Os autores chamam a atenção para o fato de que no campo da posturografia os equívocos sobre instrumentos são tão amplos e profundos que apenas recentemente tem havido artigos publicados em revistas científicas sugerindo o uso de um game como o Nintendo Wii Balance Board, em vez de instrumento como a plataforma de força para adquirir dados posturográficos. Caracterizar as ferramentas utilizadas para a pesquisa se torna 
o primeiro e provavelmente o passo mais importante na produção de pesquisa bem fundamentadas.

\subsection{Conclusão}

Os resultados deste estudo não podem ser considerados conclusivos em relação à correspondência entre a melhora do desempenho na utilização do game Yoga em relação a uma melhora real do equilíbrio estático e da capacidade funcional de mulheres idosas. É necessário levar em conta que o número de sujeitos não permite uma análise estatística conclusiva.

A plataforma de força e os testes selecionados foram sensíveis para detectar variações apresentadas pelo indivíduo no período pré e pós intervenção, no entanto a população de sujeitos ativos não permitiu detectar variação significativa na melhora dos componentes de desempenho. Há escassez de estudos envolvendo idosos ativos e os instrumentos utilizados nesta pesquisa.

Sugere-se que estudos futuros incluam idosos de diferentes gêneros, idades, capacidade funcional e condições tais como a síndrome pós-queda e fragilidade entre outras. Também é recomendável a inclusão de outros games que exijam diferentes habilidades motoras oferecidas pelo software Nintendo Wii Fit tais como Training Plus, Strength Training, Aerobics e Balance Games. Ainda assim, necessitam ser testados se outros desenhos de protocolo de seguimento em relação ao número de sessões, duração e freqüência das práticas confirmariam resultados semelhantes aos encontrados neste estudo. 


\section{REFERÊNCIAS BIBLIOGRÁFICAS ${ }^{1}$}

AGUIAR, J. L. M. et al. Análise do equilíbrio e redução do risco de queda em idosos institucionalizados após programa de exercícios fisioterapêuticos. Revista Digital Ano 13, n.119, Buenos Aires, Abr, 2008.

ALVES, A. dos S; BAPTISTA, M. R.; DANTAS, E. H. M. Os efeitos da prática de Yoga sobre a capacidade física e autonomia funcional em idosas. Fitness \& Performance Journal, V5, n.4, p.243-249, 2006.

ANIANSSON, A.; GRIMBY, G.; HEDBERG, M.; Compensatory muscle fiber hypertrophy in elderly men. Journal of Applied Physiology, Bethesda, v.73, p.812-816, 1992.

AHMED, A. A; ASHTON-MILLER, J. A. Effect of age on detecting a loss of balance in a seated whole-body balancing task. Clinical biomechanics (Bristol, Avon). v.20, n8, p.76775, 2005.

ARAÚJO, M. C. C. et al. Importância da intervenção dietética e da atividade física na modulação do IGF-I em idosos com sarcopenia. Revista Brasileira de Nutrição Esportiva, São Paulo v.1, n.2, p.94-104, Mar-Abril, 2007.

AVEIRO, M. C. et al. Os efeitos de um programa de atividade física no equilíbrio e na força muscular do quadríceps em mulheres osteoporóticas visando a melhoria da qualidade de vida. Revista Brasileira de Ciências e Movimento, V12, n.3, p.33-38, 2004.

BASTILLE, J.V.; GILL-BODY, K.M. A Yoga-based exercise program for people with chronic poststroke hemiparesis. Physical Therapy.V.84 n.1, Jan, 2004.

BELLEW, J. W. et al. Effects of a short-term dynamic balance training program in healthy older women. Journal of geriatric physical therapy. v.28, n1, p.4-8, 2005.

CARTEE, G. D. Aging skeletal muscle: response to exercise. Exercise, Sport Sciences. Reviews, v. 22, p. 91-120, 1994.

CHEN, K. M. et al. Silver Yoga exercises improved physical fitness of transitional frail elders. v.59, n5, p.364-70, 2010.

CLARK, R; KRAEMER, T. Clinical use of Nintendo Wii bowling simulation to decrease fall risk in an elderly resident of a nursing home: a case-report. Journal of Geriatric Physical Therapy. v.32, n.4, p.174-80, 2009.

CZARNECKI, K. The big tree: The next generation of video consoles offers something for everyone. Scholl Library Journal. 53 no8 Ag 2007

DORIGUETO, R. S. et al. Recorrência e persistência da vertigem posicional paroxística benigna. Brazilian Journal of Otorhinolaryngoly. 75(4):565-72, 2009.

\footnotetext{
${ }^{1}$ De acordo com a Associação Brasileira de Normas Técnicas. NBR 6023.
} 
DUARTE, M; FREITA, S. M. S. F. Revisão sobre posturografia baseada em plataforma de força para avaliação do equilíbrio. Revista brasileira de fisioterapia. V14, n3 p.183-92, 2010.

FEDER G., et al. Guidelines for the prevention of falls in people over 65. BMJ. v. 321 n.21 October, 2000.

FERRARI, Juliane F. Uso da Escala de Depressão geriatrica de Yessavage para avaliar a prevalencia de depressãoem idosos hospitalizados. Scientia Medica, V.17. Porto Alegre, 2007.

FERRAZ, M.B; OLIVEIRA, L.M; ARAUJO, P.M; ATRA.E; TUGWELL, P. Crosscultural reliability of the physical ability dimension of the health assessment questionnaire. Journal of Rheumatology. V17, n8, p.7-13, 1990.

FRANCIULLI, S. E. et al. A modalidade de assistência Centro-Dia Geriátrico: efeitos funcionais em seis meses de acompanhamento multiprofissional. Ciência Saúde Coletiva, Rio de Janeiro, v. 12, n. 2, p. 373-380, 2007.

FREITAS, S. M. S. F.; DUARTE, M. Métodos de análise do controle postural. Cap.1, p.319. São Paulo, 2006.

GAUCHARD, G. C, et al. Influence of regular proprioceptive and bioenergetc physical activities on balance control in elderly women. The Journals of Gerontology. Série A, biological sciences and medical sciences. v. 58, n.9, 2003.

GIL-GOMEZ, J. A, et al. Effectiveness of a Wii balance board-based system (eBaViR) for balance rehabilitation: a pilot randomized clinical trial in patients with acquired brain injury. Journal of neuroengineering and rehabilitation. V8, n.1 p.30, 2011.

GRANACHER, U, et al. Resistance training and neuromuscular performance in seniors. International. Journal of sports medicine. v. 30, n.9, p.652-7, 2009.

GRAVEN, L. G, et al. The physiological cost and enjoyment of Wii Fit in adolescents, young adults, and older adults. Journal of physical activity \& health. v.7, n.3, p.393-401, 2010.

GONZÁLES-FERNÁNDEZ, M. et al. Bavir, easy balance virtual rehabilitation system: a study with patients. Studies in health technology and informatics. v.154, p.61-66, 2010.

HATZITAKI, V. et al. Visual feedback training improves postural adjustments associated with moving abstacle avoidance in elderly womem. Gait \& posture. v.29, n2, p.296-9, 2009a.

HATZITAKI, V. et al. Direction-Induced effects of visually guided weight-shifting training on standing balance in the elderly. Gerontology. v.55, n.2, p.145-52, 2009b.

HIGGINS, H. C. et al. Lessons learned: staff perception of the Nintendo Wii as a health promotion tool within an aged-care and disability service. Health promotion journal of Australia: official journal of Australian Association of health promotion professionals. V.21, n.3, p.189-95, 2010. 
IBGE. Censo $2010 . \quad$ Disponível em: http://www.ibge.gov.br/home/estatistica/populacao/perfilidoso/tabela1_1.shtm. Acesso em: 28 abril. 2010.

JENSEN J.; et al. Falls among frail older people in residential care. Scand J Public Health v. 30 n. 54. 2002

KENT-BRAUN, J.A.; NG, A.V.; YOUNG, K. Skeletal Muscle Contractile And Noncontractile Components In Young And Older Women And Men. Journal of Applied Physiology, Bethesda, v.88, p.662-668, 2000.

KIM, J.H. et al. Use of virtual reality to enhance balance and ambulation in chronic stroke: A double-blind, randomized controlled study. American Journal of Physical Medicine \& Rehabilitation. v.88, p.693-701, 2009.

KRISHNAMURTHY M. N.; TELLES, S. Assessing depression following two ancient Indian interventions: effects of yoga and ayurveda on older adults in a residential home. J Gerontol Nurs. Feb; 33(2):17- 23, 2007.

LI, F. et al. Tai Chi: improving functional balance and predicting subsequent falls in older persons. Medicine and Science in sports and exercise. v.36, n.12, p.2046-52, 2004.

LIMA, L. J. C. A arte de viver e envelhecer com qualidade: interfaces da terapia ocupacional, atividades artísticas e gerontologia. 2005, 210 f. (Dissertação de Mestrado em Gerontologia). Pontifícia Universidade Católica de São Paulo, São Paulo, 2005.

LINDEMANN, U. et al. Improving balance by improving motor skills. Zeitschirift für gerontology und geriatric. v.37, n1, p.20-6, 2004.

LUUKINEN, H. et al. Risk Factors for Recurrent Falls in The Elderly in Long-Term Institutional Care. Plublic Health, v. 109, p. 57-65, 1995.

MATOS, N. M. O significado do lúdico para os idosos. Brasília, (Dissertação de Mestrado em Gerontologia), Universidade Católica de Brasília, 2006.

MATSUDO, S. M. Envelhecimento, atividade física e saúde. Centro de estudos do laboratório de aptidão física de São Caetano do Sul - CELAFISCS \& Programa Agita São Paulo R. Min. Educ. Fís. Viçosa, v.10, n.1, p. 195-209, 2002.

MCCANN, S. System showdown. Library Journal. 134 n.7 Ap. 15, 2009

MEDEIROS, V. M. L. et al. Equilíbrio, controle postural e suas alterações no idoso.

Fisioweb. Publicado em Julho, 2007. Disponível em:

http://www.wgate.com.br/conteudo/medicinaesaude/fisioterapia/variedades/idoso_fabiola.htm Acesso em: 11/07/2010.

MIYAMOTO, S.T; LOMBARDI JUNIOR, I; BERG, K.O; RAMOS, L.R; NATOUR, J. Brazilian version of the Berg balance scale. Brazilian Journal of Medical and Biological Research. V.37, n9, 2004. 
MOTA, L. M. H.; LAURINDO, I. M. M.; NETO, L. L. S. Avaliação prospectiva da qualidade de vida em uma coorte de pacientes com artrite reumatóide inicial. Revista brasileira de reumatologia. V50, n.3, p.249-61, 2010.

MOUWAD, M. R. et al. Wii-based movement therapy to promote improved upper extremity function post-stroke: a pilot study. Journal of rehabilitation medicine. V43, n6 p.527-33, 2011.

NITZ, J. C. et al. Wii Fit a new-generation tool for improving balance, health and wellbeing? A pilot study. Climacteric: The journal of international menopause society. V13, n.5 p. 487-91, 2010.

OVERSTALL, P. W. The use of balance training in elderly people with falls. Reviews in Clinical Gerontology v.13, p.153-161, 2003.

ÖZGÜRBÜZ, C. Osteoporosis and physical activity. Turkish Journal of Endocrinology and Metabolism. v.3, p.101-105, 2003.

PAGNACCO G, OGGERO E, WRIGHT CH. Biomedical instruments versus toys:a preliminary comparison of force platforms and the nintendo wii balance board. Biomedical Science Instrumental. V.47, p.12-7, 2011.

PAIXÃO JR, C. M.; REICHENHEIM, M. E. Uma revisão sobre instrumentos de avaliação do estado funcional do idoso. Cad. Saúde Pública, Rio de Janeiro, 21(1):7-19, jan-fev, 2005

PIERCE, J.B. Once and future classics. American Libraries. v.39, n.7, p.80-81, Aug, 2008.

PORTER, M. M.; VANDERVOORT, A. A.; LEXELL, J. Aging of humanmuscle: structure, function and adaptability. Scandinavian. Journal of Medicine \& Science in Sports, v. 5, p. 129-142, 1995.

PERSCH, L.N, et al. Strength training improves fall-related gait kinematics in the elderly: a randomized controlled trial. Clinical biomechanics (Bristol, Avon). v.24, n.10, p.819-25, 2009.

PERRACINI, M. R.; FLO, C. M. Funcionalidade e Envelhecimento. 1. ed. Rio de Janeiro: Guanabara Koogan. V.1, p.538, 2009.

PERRACINI, M. R. Planejamento e adaptação do ambiente para pessoas idosas. In: Tratado de Geriatria e Gerontologia. Rio de Janeiro: Guanabara Koogan. P.799, 2002.

PODSIADLO, D; RICHARDSON, S. The timed “Up \& Go": a test of basic functional mobility for frail elderly persons. J Am Geriatr Soc. V39, n2, p.142-8, 1991.

RESENDE, S.M.; RASSI, C.M.; VIANA, F.P. Efeitos da hidroterapia na recuperação do equilíbrio e prevenção de quedas em idosas. Revista Brasileira de Fisioterapia. V12, n.1, 2008. 
RUNGE, M; REHFELD, G; RESNICEK, E. Balance training and exercise in geriatric patients. Journal of musculoskeletal patients. V1, p.54-58, 2000.

RUBENSTEIN, L. Z., JOSEPHSON, K. R. The Epidemiology of Falls and Syncope. Clinics in Geriatric Medicine, v. 18, p. 141-158, 2002.

RYDWIK, E.; FRANDIN, K.; AKNER, G. Effects of physical training on physical performance in institutionalized elderly patients with multiple diagnoses. Age-Ageing. V.33 p.13-23, 2004.

SAPOSNIK, G, et al. Effectiveness of virtual reality using Wii gaming technology in stroke rehabilitation: A pilot randomized clinical trial and proof of principle. Stroke: A Journal of cerebral circulation. v.41, n.7, p.1477-84, 2010a.

SAPOSNIK, G, et al. Effectiveness of virtual reality exercises in stroke rehabilitation (EVREST): rationale, design, and protocol of a pilot randomized clinical trial assessing the Wii gaming system. International Journal of Stroke v.5, n.1, p.47-51, 2010b.

SCHIMID, A. A. et al. Effects of a 12 week Yoga intervention on fear of falling and balance on older adults: a pilot study. Archives of physical medicine and rehabilitation. v. 91, n. 4, p.576-583, 2010.

SILVA, A.; ALMEIDA, G.J.M.; CASSILHAS, R.C.; COHEN, M.; PECCIN, M.S.; TUFIK, S.; MELLO, M.T. Equilibrio, coordenação e agilidade de idosos submetidos a pratica de exercícios físicos resistidos. Revista Brasileira de Medicina do Esporte. V14, n.2, 2008.

SMITH LK, WEISS EL, LEHMKUHL LD. Cinesiologia clínica de Brunnstom. São Paulo: Manole; 1997.

THORBAHN, L. D. B.; NEWTON, R; A. Use of the Berg Balance Test to Predict Falls in Elderly Persons. Physical Therapy. 76:1124-1126, 1996.

TRAN, M.D. et al. Effects of hatha yoga practice on the health-related aspects of physical fitness. Preventive Cardiology. v.4, n.4, p.165-170, 2001.

TRELEAVEN, J. Dizziness Handicap Inventory (DHI). Australian Journal of Physiotherapy. V52, 2006.

TSANG, W. W; HUI-CHAN, C.W. Effect of 4- and 8-wk intensive Tai Chi training on balance control in the elderly. Medicine and Science in sports and exercise. v.36, n.4, p.64857, 2004a.

WALSH, M.C. et al. Sarcopenia in premenopausal women with osteopenia, osteoporosis and normal bone mineral density. Osteoporosis International, n.17, p.61-67, 2006.

YENG, L.T. et al. Medicina física e reabilitação em doentes com dor crônica. Dor: Manual para o clínico, Cap.13, p.120, 2001. 
YONG JOO, et al. A feasibility study using interactive commercial off-the-shelf computer gaming in the upper limb rehabilitation in patients after stroke. Journal of rehabilitation medicine. v. 42, n.5, p.437-41, 2010.

ZAMBALDI, P.A; COSTA, T.A.B.N; DINIZ, G.C.L.M; SCLAZO, P.L. Efeito de um treinamento, de equilíbrio em um grupo de mulheres idosas da comunidade: estudo piloto de uma abordagem específica, não sistematizado breve. Acta Fisiátrica, V14, n1, p.17-24, 2007.

ZATSIORSKY, V. M. Kinematics of human motion. Champaign: Human Kinetics; 1998.

\section{REFERENCIAS DA ESTATÍSTICA}

Disponível em: http://www.r-project.org; Acesso em 09/11/2011.

SAS Institute Inc., SAS/STAT® User's Guide, Version 9, Cary, NC: SAS Institute Inc., 2003;

SCHALL, R. Estimation in generalized linear models with random effects. Biometrika, v. 78, n.4, p. 719-727, 1991. 
ANEXO A

QUESTIONÁRIO INICIAL

1. NOME: DATA

ENDEREÇO:

BAIRRO: TELEFONE:

ESTADO CIVIL:

2. SEXO: $\square$ MASCULINO $\square$ FEMININO.

3. DATA DE NASCIMENTO:

4. ESCOLARIDADE:

$\square 1^{\circ}$ grau incompleto

$1^{\circ}$ grau completo

$2^{\circ}$ grau incompleto

$2^{\circ}$ grau completo

Superior incompleto

Superior completo

5. ATUAÇÃO PROFISSIONAL:

Aposentado

outras:

6. RESIDE COM:

$\square$ Família

Amigos

Instituições

$\square$ Outros

7. PRATICA ATIVIDADES FÍSICAS?

Sim

Não

HÁ QUANTO TEMPO PRATICA?

(SE SUA RESPOSTA ANTERIOR FOI NÃO VÁ PARA A PERGUNTA N¹0)

8. TIPO DE ATIVIDADE EXERCIDA.

$\square$ Caminhada

Corrida

Academia

Yoga

Outros

9. FREQUÊNCIA:

1 vez / semana

2 vezes / semana

3 vezes / semana

4 vezes / semana

5 vezes / semana

Mais de 5 vezes / semana

10. TEVE QUEDAS NOS ÚLTIMOS 6 MESES? QUANDO?

$\square$ Há 1 semana

$\square$ há 1 mês

há 2 meses

há 3 meses

há 4 meses

há $5 / 6$ meses

11. TEM ALGUMA DOENÇA?

$\square \operatorname{Sim}$

$\square$ Não

Especifique:

12. POSSUI DOR OU DIFICULDADE EM MOVIMENTAR ALGUMA PARTE DO CORPO?

$\square \quad$ Sim

3. POSSUI ALGUM PROBLEMA DE VISÃO OU AUDIÇÃO?

$\square \quad \operatorname{Sim}$

OBS:

14. USA ALGUM ACESSÓRIO QUE AUXILIE NO DESEMPENHO DAS ATIVIDADES DO COTIDIANO: 
Óculos / lentes

bengalas / muletas

próteses / órteses

aparelhos de audição

cadeira de rodas / andador

adaptadores especiais

outros

15. SENTE TONTURAS OU DESMAIOS? SIM $\quad \mathrm{Y} \quad \square$
COM QUE FREQUENCIA?

$\square$ O tempo todo

quando viro a cabeça de forma rápida

Sempre quando viro a cabeça

sempre quando sento ou levanto

às vezes quando sento ou levanto

quando fico irritado

outros

16. PASSOU POR ALGUMA CIRURGIA RECENTEMENTE:

$\square$ Sim

$\square$ Não

17. FAZ USO DE ALGUM TIPO DE MEDICAÇÃO?

$\square$ Sim

$\square$ Não

18. QUAL A FINALIDADE

19. HÁ QUANTO TEMPO FAZ USO DESSA MEDICAÇÃO? 
ANEXO B

ÍNDICE DE MASSA CORPOREA

1. NOME: DATA

PESO: ALTURA:

IMC:

\begin{tabular}{|l|l|}
\hline & \\
\hline Abaixo de 18,5 & Você está abaixo do peso ideal \\
\hline Entre 18,5 e 24,9 & Parabéns — você está em seu peso normal! \\
\hline Entre 25,0 e 29,9 & Você está acima de seu peso (sobrepeso) \\
\hline Entre 30,0 e 34,9 & Obesidade grau I \\
\hline Entre 35,0 e 39,9 & Obesidade grau II \\
\hline 40,0 e acima & Obesidade grau III \\
\hline
\end{tabular}

http://como-emagrecer.com/calculo-de-imc.html 
ANEXO C

NOME:

TESTE DE TONTURA RELATADA DIZZINESS HANDICAP INVENTARY - DHI (Brasileiro)

NOME DO ENTREVISTADOR:

01- Olhar para cima piora a sua tontura?

$\square \operatorname{Sim}$

Não

Às vezes

02- Você se sente frustrado(a) devido a sua tontura?

$\operatorname{Sim}$

Não

Às vezes

03- Você restringe suas viagens de trabalho ou lazer por causa da tontura?

Sim

Não

Às vezes

04- Andar pelo corredor de um supermercado piora a sua tontura?

Sim

Não

Às vezes

05- Devido a sua tontura, você tem dificuldade ao deitar-se ou levantar-se da cama?

Sim

$\square$ Não

Às vezes

06- Sua tontura restringe significativamente sua participação em atividades sociais tais como: sair para jantar, ir ao cinema, dançar ou ir a festas?

$\square \operatorname{Sim}$

Não

Às vezes

07- Devido a sua tontura, você tem dificuldade para ler?

$\square \operatorname{Sim}$

Não

Às vezes

08- Sua tontura piora quando você realiza atividades mais difíceis como esporte, dançar, trabalhar em atividades domésticas tais como varrer e guardar a louça?

$\square \operatorname{Sim}$

$\square$ Não

Às vezes

09- Devido a sua tontura, você tem medo de sair de casa sem ter alguém que o acompanhe?

$\operatorname{Sim}$

Não

Às vezes

10- Devido a sua tontura, você se sente envergonhado na presença de outra pessoa?

$\operatorname{Sim}$

Não 
Às vezes

11- Movimentos rápidos de sua cabeça pioram a sua tontura?

$\square$ Sim

Não

Às vezes

12- Devido a sua tontura, você evita lugares altos?

$\square \operatorname{Sim}$

Não

Às vezes

13- Virar-se na cama piora a sua tontura?

Sim

Não

Às vezes

14- Devido a sua tontura, é difícil para você realizar trabalhos domésticos pesados ou cuidar do quintal?

$\square \operatorname{Sim}$

Não

Às vezes

15- Por causa da sua tontura, você teme que as pessoas achem que você esta drogado(a) ou bêbado(a)?

Sim

Não

Às vezes

16- Devido a sua tontura, é difícil para você sair para caminhar sem ajuda?

Sim

$\square$ Não

Às vezes

17- Caminhar na calçada piora a sua tontura?

Sim

Não

Às vezes

18- Devido a sua tontura, é difícil para você se concentrar?

$\square \operatorname{Sim}$

Não

Às vezes

19- Devido a sua tontura, é difícil para você andar pela casa no escuro?

$\square \operatorname{Sim}$

Não

Às vezes

20- Devido a sua tontura, você tem medo de ficar em casa sozinho(a)?

$\square$ Sim

Não

Às vezes

21- Devido a sua tontura, você se sente incapacitado?

$\square$ Sim

Não

Às vezes 
22- Sua tontura prejudica sua relação com membros de sua família ou amigos?

$\square \operatorname{Sim}$

$\square$ Não

$\square$ Às vezes

23- Devido a sua tontura, você está deprimido?

$\square \operatorname{Sim}$

$\square$ Não

Às vezes

24- Sua tontura interfere em seu trabalho ou responsabilidades em casa?

$\square \operatorname{Sim}$

Não

Às vezes

25- Inclinar-se piora a sua tontura?

$\square \operatorname{Sim}$

$\square$ Não

Às vezes

SIM= 4 PONTOS

ÀS VEZES= 2 PONTOS

NÃO= 0 PONTOS 
ANEXO D

Escala de Depressão Geriátrica - GDS 15

NOME:

DATA:

NOME DO ENTREVISTADOR:

1- $\mathrm{O}$ (a) $\mathrm{Sr}(\mathrm{a})$ esta satisfeito (a) com sua vida?

$\square$ SIM

$\square \quad$ NÃO

2- $\mathrm{O}$ (a) $\mathrm{Sr}(\mathrm{a})$ diminuiu a maior parte de suas atividades e interesse?

$\square$ SIM

$\square$ NÃO

3- $\mathrm{O}(\mathrm{a}) \mathrm{Sr}(\mathrm{a})$ sente que a vida esta vazia?

$\square$ SIM

NÃO

4- $\mathrm{O}(\mathrm{a}) \mathrm{Sr}(\mathrm{a})$ geralmente se sente aborrecido(a)?

$\square$ SIM

NÃO

5- $\mathrm{O}(\mathrm{a}) \mathrm{Sr}(\mathrm{a})$ se sente animado(a) a maior parte do tempo?

$\square$ SIM

NÃO

6- $\mathrm{O}(\mathrm{a}) \mathrm{Sr}(\mathrm{a})$ tem medo que alguma coisa ruim possa lhe acontecer?

$\square$ SIM

NÃO

7- $\mathrm{O}(\mathrm{a}) \mathrm{Sr}(\mathrm{a})$ se sente feliz a maior parte do tempo?

SIM

NÃO

8- $\mathrm{O}(\mathrm{a}) \mathrm{Sr}(\mathrm{a})$ se sente frequentemente desamparado?

$\square$ SIM

NÃO

9- $\mathrm{O}(\mathrm{a}) \mathrm{Sr}(\mathrm{a})$ prefere ficar em casa do que sair e fazer coisas novas?

SIM

NÃO

10- $\mathrm{O}$ (a) $\mathrm{Sr}$ (a) acha que tem mais problemas de memória do que a maioria?

SIM

NÃO

11- O(a) Sr(a) acha bom estar vivo?

SIM

NÃO

12- $\mathrm{O}(\mathrm{a}) \operatorname{Sr}(\mathrm{a})$ se sente inútil ou incapaz do modo que esta agora?

SIM

NÃO

13- $\mathrm{O}(\mathrm{a}) \mathrm{Sr}(\mathrm{a})$ se sente cheio de energia?

SIM

NÃO

14- $\mathrm{O}(\mathrm{a}) \mathrm{Sr}(\mathrm{a})$ e desesperançoso(a)? 
NÃO

15- $\mathrm{O}(\mathrm{a}) \mathrm{Sr}(\mathrm{a})$ acha que a maioria das pessoas é melhor que o sr(a)?

$\square$ SIM

$\square$ NÃO 
ANEXO E

Time Up and Go Test

NOME:

DATA

NOME DO ENTREVISTADOR:

Tempo que o sujeito percorreu (segundos):

OBS: 
ANEXO F

Escala de equilíbrio de Berg (EEB) - Versão Brasileira

NOME:

DATA:

NOME DO ENTREVISTADOR:

1. SENTADO PARA EM PÉ

INSTRUÇÕES: Por favor, fique de pé. Tente não usar suas mãos como suporte.

( ) 4 capaz de permanecer em pé sem o auxílio das mãos e estabilizar de maneira independente

( ) 3 capaz de permanecer em pé independentemente usando as mãos

( ) 2 capaz de permanecer em pé usando as mão após várias tentativas

( ) 1 necessidade de ajuda mínima para ficar em pé ou estabilizar

( ) 0 necessidade de moderada ou máxima assistência para permanecer em pé

\section{EM PÉ SEM APOIO}

INSTRUÇÕES: Por favor, fique de pé por dois minutos sem se segurar em nada.

( ) 4 capaz de permanecer em pé com segurança por 2 minutos

( ) 3 capaz de permanecer em pé durante 2 minutos com supervisão

( ) 2 capaz de permanecer em pé durante 30 segundos sem suporte

( ) 1 necessidade de várias tentativas para permanecer 30 segundos sem suporte

( ) 0 incapaz de permanecer em pé por 30 segundos sem assistência

Se o sujeito é capaz de permanecer em pé por 2 minutos sem apoio, marque pontuação máxima na situação sentado sem suporte. Siga diretamente para o item \#4.

\section{SENTADO SEM SUPORTE PARA AS COSTAS, MAS COM OS PÉS APOIADOS SOBRE O CHÃO OU SOBRE} UM BANCO

INSTRUÇÕES: Por favor, sente-se com os braços cruzados durante 2 minutos.

( ) 4 capaz de sentar com segurança por 2 minutos

( ) 3 capaz de sentar com por 2 minutos sob supervisão

( ) 2 capaz de sentar durante 30 segundos

( ) 1 capaz de sentar durante 10 segundos

( ) 0 incapaz de sentar sem suporte durante 10 segundos

\section{EM PÉ PARA SENTADO}

- INSTRUÇÕES: Por favor, sente-se.

( ) 4 senta com segurança com o mínimo uso das mão

( ) 3 controla descida utilizando as mãos

( ) 2 apóia a parte posterior das pernas na cadeira para controlar a descida

( ) 1 senta independentemente mas apresenta descida descontrolada

( ) 0 necessita de ajuda para sentar

\section{TRANSFERÊNCIAS}

INSTRUÇÕES: Pedir ao sujeito para passar de uma cadeira com descanso de braços para outra sem descanso de braços (ou uma cama)

( ) 4 capaz de passar com segurança com o mínimo uso das mãos

( ) 3 capaz de passar com segurança com uso das mãos evidente

( ) 2 capaz de passar com pistas verbais e/ou supervisão

( ) 1 necessidade de assistência de uma pessoa

( ) 0 necessidade de assistência de duas pessoas ou supervisão para segurança

6. EM PÉ SEM SUPORTE COM OLHOS FECHADOS

INSTRUÇÕES: Por favor, feche os olhos e permaneça parado por 10 segundos 
( ) 4 capaz de permanecer em pé com segurança por 10 segundos

( ) 3 capaz de permanecer em pé com segurança por 10 segundos com supervisão

( ) 2 capaz de permanecer em pé durante 3 segundos

( ) 1 incapaz de manter os olhos fechados por 3 segundos mas permanecer em pé

( ) 0 necessidade de ajuda para evitar queda

\section{EM PÉ SEM SUPORTE COM OS PÉS JUNTOS}

INSTRUÇÕES: Por favor, mantenha os pés juntos e permaneça em pé sem se segurar

( ) 4 capaz de permanecer em pé com os pés juntos independentemente com segurança por 1 minuto

( ) 3 capaz de permanecer em pé com os pés juntos independentemente com segurança por 1 minuto, com supervisão

( ) 2 capaz de permanecer em pé com os pés juntos independentemente e se manter por 30 segundos

( ) 1 necessidade de ajuda para manter a posição mas capaz de ficar em pé por 15 segundos com os pés juntos

( ) 0 necessidade de ajuda para manter a posição mas incapaz de se manter por 15 segundos

\section{ALCANCE A FRENTE COM OS BRAÇOS EXTENDIDOS PERMANECENDO EM PÉ}

INSTRUÇÕES: Mantenha os braços estendidos a 90 graus. Estenda os dedos e tente alcançar a maior distância possível. (o examinador coloca uma régua no final dos dedos quando os braços estão a 90 graus. Os dedos não devem tocar a régua enquanto executam a tarefa. A medida registrada é a distância que os dedos conseguem alcançar enquanto o sujeito está na máxima inclinação para frente possível. Se possível, pedir ao sujeito que execute a tarefa com os dois braços para evitar rotação do tronco.)

( ) 4 capaz de alcançar com confiabilidade acima de $25 \mathrm{~cm}$ (10 polegadas)

( ) 3 capaz de alcançar acima de 12,5cm (5 polegadas)

( ) 2 capaz de alcançar acima de $5 \mathrm{~cm}$ (2 polegadas)

( ) 1 capaz de alcançar mas com necessidade de supervisão

( ) 0 perda de equilíbrio durante as tentativas / necessidade de suporte externo

\section{APANHAR UM OBJETO DO CHÃO A PARTIR DA POSIÇÃO EM PÉ}

INSTRUÇÕES: Pegar um sapato/chinelo localizado a frente de seus pés

( ) 4 capaz de apanhar o chinelo facilmente e com segurança

( ) 3 capaz de apanhar o chinelo mas necessita supervisão

( ) 2 incapaz de apanhar o chinelo mas alcança 2-5cm (1-2 polegadas) do chinelo e manter o equilíbrio de maneira independente

( ) 1 incapaz de apanhar e necessita supervisão enquanto tenta

( ) 0 incapaz de tentar / necessita assistência para evitar perda de equilíbrio ou queda

\section{EM PÉ, VIRAR E OLHAR PARA TRÁS SOBRE OS OMBROS DIREITO E ESQUERDO}

INSTRUÇÕES: Virar e olhar para trás sobre o ombro esquerdo. Repetir para o direito. O examinador pode pegar um objeto para olhar e colocá-lo atrás do sujeito para encorajá-lo a realizar o giro.

( ) 4 olha para trás por ambos os lados com mudança de peso adequada

( ) 3 olha para trás por apenas um dos lados, o outro lado mostra menor mudança de peso

( ) 2 apenas vira para os dois lados mas mantém o equilíbrio

( ) 1 necessita de supervisão ao virar

( ) 0 necessita assistência para evitar perda de equilíbrio ou queda

\section{VIRAR EM 360 GRAUS}

INSTRUÇÕES: Virar completamente fazendo um círculo completo. Pausa. Fazer o mesmo na outra direção

( ) 4 capaz de virar 360 graus com segurança em 4 segundos ou menos

( ) 3 capaz de virar 360 graus com segurança para apenas um lado em 4 segundos ou menos

( ) 2 capaz de virar 360 graus com segurança mas lentamente

( ) 1 necessita de supervisão ou orientação verbal 
( ) 0 necessita de assistência enquanto vira

\section{COLOCAR PÉS ALTERNADOS SOBRE DEGRAU OU BANCO PERMANECENDO EM PÉ E SEM APOIO}

INSTRUÇÕES: Colocar cada pé alternadamente sobre o degrau/banco. Continuar até cada pé ter tocado o degrau/banco quatro vezes.

( ) 4 capaz de ficar em pé independentemente e com segurança e completar 8 passos em 20 segundos

( ) 3 capaz de ficar em pé independentemente e completar 8 passos em mais de 20 segundos

( ) 2 capaz de completar 4 passos sem ajuda mas com supervisão

( ) 1 capaz de completar mais de 2 passos necessitando de mínima assistência

( ) 0 necessita de assistência para prevenir queda / incapaz de tentar

\section{PERMANECER EM PÉ SEM APOIO COM OUTRO PÉ A FRENTE}

INSTRUÇÕES: (DEMOSTRAR PARA O SUJEITO) Colocar um pé diretamente em frente do outro. Se você perceber que não pode colocar o pé diretamente na frente, tente dar um passo largo o suficiente para que o calcanhar de seu pé permaneça a frente do dedo de seu outro pé. (Para obter 3 pontos, o comprimento do passo poderá exceder o comprimento do outro pé e a largura da base de apoio pode se aproximar da posição normal de passo do sujeito).

( ) 4 capaz de posicionar o pé independentemente e manter por 30 segundos

( ) 3 capaz de posicionar o pé para frente do outro independentemente e manter por 30 segundos

( ) 2 capaz de dar um pequeno passo independentemente e manter por 30 segundos

( ) 1 necessidade de ajuda para dar o passo mas pode manter por 15 segundos

( ) 0 perda de equilíbrio enquanto dá o passo ou enquanto fica de pé

\section{PERMANECER EM PÉ APOIADO EM UMA PERNA}

INSTRUÇÕES: Permaneça apoiado em uma perna o quanto você puder sem se apoiar

( ) 4 capaz de levantar a perna independentemente e manter por mais de 10 segundos

( ) 3 capaz de levantar a perna independentemente e manter entre 5 e 10 segundos

( ) 2 capaz de levantar a perna independentemente e manter por 3 segundos ou mais

( ) 1 tenta levantar a perna e é incapaz de manter 3 segundos, mas permanece em pé independentemente

( ) 0 incapaz de tentar ou precisa de assistência para evitar queda 
ANEXO G

Health Assessment Questionnaraire (HAQ)

NOME DATA

NOME DO AVALIADOR:

Nessa seção estamos interessados em saber como sua doença afeta suas habilidades funcionais do cotidiano. Por favor, sintase livre para adicionar qualquer comentário no verso da pagina.

Por favor, coloque a resposta que melhor descreve suas habilidades usuais NA ÚLTIMA SEMANA.

$\begin{array}{cccc}\text { Sem QUALQUER } & \text { Com ALGUMA } & \text { Com MUITA } & \text { INCAPAZ } \\ \text { dificuldade }^{\circ} & \underline{\text { dificuldade }}^{1} & \text { dificuldade }^{2} & \underline{\text { de realizar }^{2}}\end{array}$

1- VESTIR-SE \& PREPARAR-SE

\section{Você está hábil a:}

-vestir-se sozinho incluindo

amarrar sapatos e abotoar?

- passar shampoo?

2- LEVANTAR

Você está hábil a:

- levantar-se de uma cadeira reta?

- deitar e levantar da cama?

3- COMER

Você está hábil a:

-cortar a carne?

-levar um copo ou xícara cheia até a boca?

-abrir uma nova embalagem de leite?

4- ANDAR

Você está hábil a:

-andar ao ar livre em terreno plano?

-subir 5 degraus?

Por favor, coloque qualquer AUXÍLIO ou DISPOSITIVO que você geralmente usa para alguma dessas atividades.

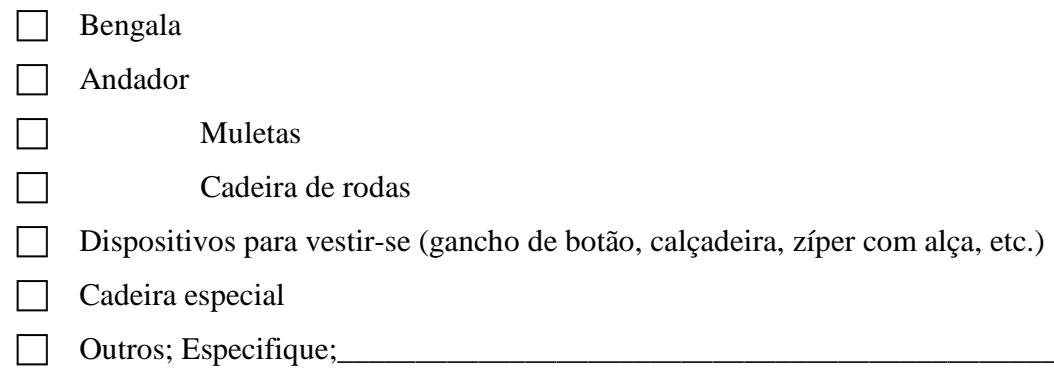

Por favor, marque a categoria em que você geralmente precisa de AJUDA DE OUTRA PESSOA:

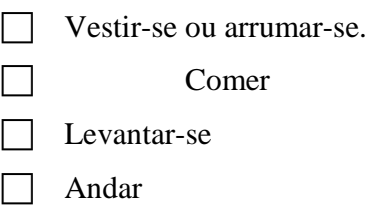

Por favor, coloque a resposta que melhor descreve suas habilidades usuais NA SEMANA PASSADA.

5- HIGIENE

$\begin{array}{cccc}\text { Sem QUALQUER } & \text { Com ALGUMA } & \text { Com MUITA } & \text { INCAPAZ } \\ \text { dificuldade }^{\circ} & \underline{\text { dificuldade }^{1}} & \underline{\text { dificuldade }^{2}} & \underline{\text { de realizar }^{3}}\end{array}$

Você esta hábil a: 
- Lavar e secar seu corpo?

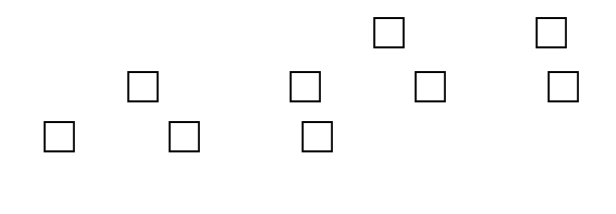

- Tomar banho

de banheira?

6- ALCANÇE

Você esta hábil a:

- Alcançar e descer um objeto de

5 quilos (como um saco de açúcar)

a partir de cima da sua cabeça?

- Abaixar para pegar roupas do chão?

7- PREENSÃO

Você esta hábil a:

- Abrir porta de carros?

- Abrir frascos que já foram

abertos previamente?

- Abrir e fechar torneiras?

8- ATIVIDADES

Você esta hábil a:

- Sair a rua e fazer compras?

- Entrar e sair do carro?

- Tarefas como aspirar ou

Cuidar do jardim?

Por favor, marque qualquer AJUDA OU DISPOSITIVO que você geralmente usa para qualquer dessas atividades.

Sentar no sanitário

Fechar a banheira

Sentar na banheira

Aparelhos com cabo longo para alcançar

Abrir frascos (previamente abertos)

Aparelhos com cabo longo no banheiro

Outros (especifique):

Por favor, marque a categoria que você geralmente precisa de AJUDA DE OUTRAS PESSOAS:

Higiene

Agarrar e abrir coisas

Alcançar

Recados e tarefas 
ANEXO H

Teste de Romberg clássico

NOME:

DATA:_L_

NOME DO ENTREVISTADOR:

Individuo com os calcanhares unidos e a ponta dos pés separados a $30^{\circ}$ devem permanecer com as mãos ao longo do corpo com os olhos fechados por 1 minuto. O teste é considerado positivo se houver queda.

ROMBERG PRESENTE

ROMBERG AUSENTE 
ANEXO I

Teste de Romberg sobre a Plataforma de Força

NOME:

NOME DO ENTREVISTADOR:

DATA: 1

$1^{\mathrm{a}}$ Posição) Bipodal - olhos abertos - superfície firme por 30 segundos.

Não consegue

Consegue

TEMPO MARCADO:

$2^{\text {a }}$ Posição) Bipodal - olhos abertos - superfície instável (espuma) por 30 segundos.

Não consegue

Consegue

TEMPO MARCADO:

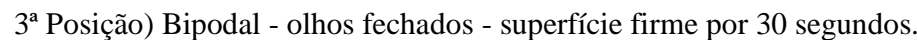

$\square$ Não consegue

Consegue

TEMPO MARCADO:

$4^{\mathrm{a}}$ posição) Bipodal - olhos fechados - superfície instável (espuma) por 30 segundos.

Não consegue

Consegue

TEMPO MARCADO:

$5^{\text {a }}$ Posição) Bipodal sensibilizado - olhos abertos - superfície firme, por 30 segundos.

Não consegue

Consegue

TEMPO MARCADO:

6a Posição) Bipodal sensibilizado - olhos abertos - superfície instável (espuma), por 30 segundos.

$\square$ Não consegue

Consegue

TEMPO MARCADO:

$7^{\text {a }}$ Posição) Bipodal sensibilizado - olhos fechados - superfície firme, por 30 segundos.

$\square$ Não consegue

$\square$ Consegue

TEMPO MARCADO:

$8^{\text {a }}$ Posição) Bipodal sensibilizado - olhos fechados - superfície instável (espuma), por 30 segundos.

$\square$ Não consegue

Consegue

TEMPO MARCADO:

9a Posição) Unipodal (pé direito) - olhos abertos - superfície firme por 30 segundos.

Não consegue

Consegue

TEMPO MARCADO:

$10^{\text {a }}$ Posição) Unipodal (pé direito) - olhos abertos - superfície instável (espuma) por 30 segundos

$\square$ Não consegue

$\square$ Consegue

TEMPO MARCADO:

11 $1^{\text {a }}$ Posição) Unipodal (pé direito) - olhos fechados - superfície firme por 30 segundos.

$\square$ Não consegue

$\square$ Consegue

TEMPO MARCADO:

$12^{a}$ Posição) Unipodal (pé direito) - olhos fechados - superfície instável (espuma) por 30 segundos.

$\square$ Não consegue

Consegue

TEMPO MARCADO:

$13^{\text {a }}$ Posição) Unipodal (pé esquerdo) - olhos abertos - superfície firme por 30 segundos 
Não consegue

Consegue

TEMPO MARCADO:

14 Posição) Unipodal (pé esquerdo) - olhos abertos - superfície instável (espuma) por 30 segundos

$\square$ Não consegue

Consegue

TEMPO MARCADO:

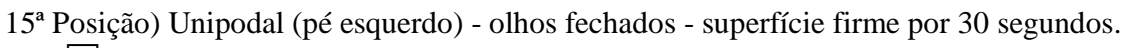

$\square$ Não consegue

Consegue

TEMPO MARCADO:

$16^{\text {a }}$ Posição) Unipodal (pé esquerdo) - olhos fechados - superfície instável (espuma) por 30 segundos..

Não consegue

Consegue

TEMPO MARCADO: 
ANEXO J

Lista De Checagem (Checklist)

NOME: DATA:

NOME DO ENTREVISTADOR:

1- ALIMENTOU-SE NORMALMENTE HOJE?

SIM

$\square$ NÃO

HÁ QUANTO TEMPO?

2- TEVE UMA BOA NOITE DE SONO?

$\square$ SIM

NÃO

DURMIU QUANTO TEMPO?

3- APRESENTA VESTUÁRIO ADEQUADO PARA PRÁTICA DE EXERCÍCIOS?

$\square$ SIM

$\square \quad$ NÃO

APRESENTA LIMITAÇÕES? ONDE?

4- UTILIZA ACESSÓRIOS QUE AUXILIE NO DESEMPENHO DAS ATIVIDADES COTIDIANAS CITADAS NA AVALIAÇÃO INICIAL?

$\square$ SIM

$\square$ NÃO

QUAIS?

5 - SOFREU DE ALGUMA DOENÇA OU QUEDA APÓS A ÚLTIMA SESSÃO?

SIM

$\square \quad \mathrm{NÃO}$

6 - FEZ USO DE SEUS MEDICAMENTOS ROTINEIROS?

$\square$ SIM

NÃO

7 - APRESENTOU ALGUM PROBLEMA IMPREVISTO NOS ÚLTIMOS DIAS.

SIM

$\square$ NÃO

DESCREVA: 
ANEXO K

Tabela com pontuação das posturas de Yoga.

NOME:

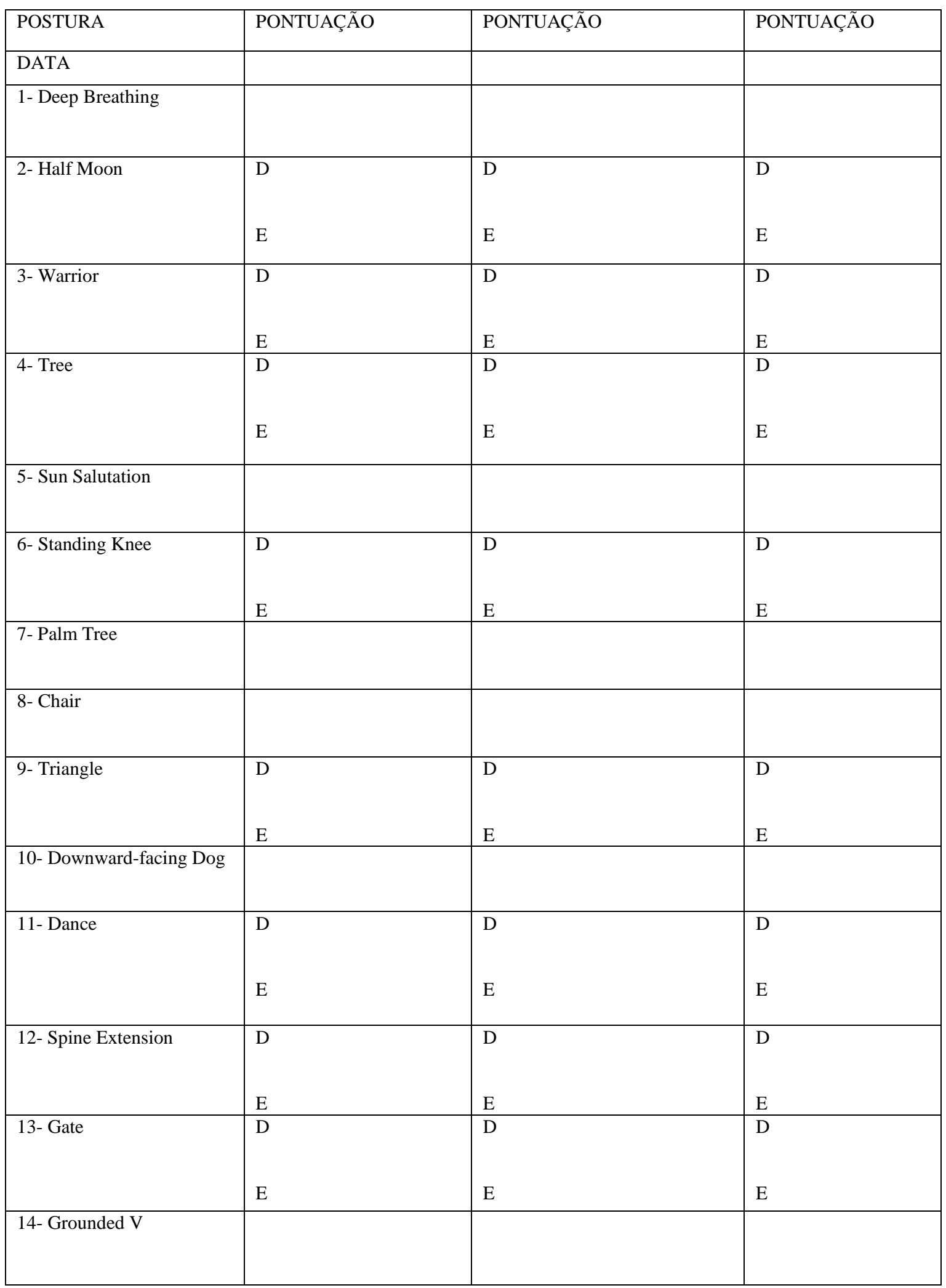


ANEXO L

QUESTIONARIO DE AVALIAÇÃO DA SATISFAÇÃO

NOME:

DATA:

O SR(A) FICOU SATISFEITA COM A UTILIZAÇÃO DA NINTENDO WII (YOGA)?

O SR(A) SENTIU ALGUM BENEFÍCIO APÓS A UTILIZAÇÃO DO NINTENDO WII (YOGA)? QUAL?

O SR(A) USARIA NOVAMENTE O NINTENDO WII? PARA QUAL FINALIDADE?

O SR(A) INDICARIA O NINTENDO WII PARA CONHECIDOS?

CLASSIFIQUE SUA SATISFAÇÃO COM O EQUILIBRIO ALCANÇADO NUMA ESCALA DE 0 A 10.

0 10 
ANEXO M

TABELAS COM PONTUAÇÃO DOS BERG DE TODOS OS USUÁRIOS

\begin{tabular}{|l|c|c|}
\hline Grupo de tarefas de Berg & Pontuação pré intervenção & Pontuação pós intervenção \\
\hline Berg (pontuação total) & 51 & 54 \\
\hline Base de sustentação & 11 & 12 \\
\hline Componentes rotacionais & 10 & 11 \\
\hline Alcance funcional & 4 & 16 \\
\hline Provas estacionarias & 16 & 11 \\
\hline Transferências & 10 & 4 \\
\hline
\end{tabular}

Participante 2

\begin{tabular}{|l|c|c|}
\hline Grupo de tarefas de Berg & Pontuação pré intervenção & Pontuação pós intervenção \\
\hline Berg (pontuação total) & 55 & 56 \\
\hline Base de sustentação & 12 & 12 \\
\hline Componentes rotacionais & 11 & 4 \\
\hline Alcance funcional & 4 & 16 \\
\hline Provas estacionarias & 16 & 12 \\
\hline Transferências & 12 & \\
\hline
\end{tabular}

Participante 3

\begin{tabular}{|l|c|c|}
\hline Grupo de tarefas de Berg & Pontuação pré intervenção & Pontuação pós intervenção \\
\hline Berg (pontuação total) & 55 & 56 \\
\hline Base de sustentação & 12 & 12 \\
\hline Componentes rotacionais & 11 & 4 \\
\hline Alcance funcional & 4 & 16 \\
\hline Provas estacionarias & 16 & 12 \\
\hline Transferências & 12 & \\
\hline
\end{tabular}

Participante 4

\begin{tabular}{|l|c|c|}
\hline Grupo de tarefas de Berg & Pontuação pré intervenção & Pontuação pós intervenção \\
\hline Berg (pontuação total) & 53 & 56 \\
\hline Base de sustentação & 11 & 12 \\
\hline
\end{tabular}




\begin{tabular}{|l|c|c|}
\hline Componentes rotacionais & 12 & 12 \\
\hline Alcance funcional & 4 & 4 \\
\hline Provas estacionarias & 16 & 16 \\
\hline Transferências & 10 & 12 \\
\hline
\end{tabular}

Participante 5

\begin{tabular}{|l|c|c|}
\hline Grupo de tarefas de Berg & Pontuação pré intervenção & Pontuação pós intervenção \\
\hline Berg (pontuação total) & 49 & 52 \\
\hline Base de sustentação & 9 & 11 \\
\hline Componentes rotacionais & 9 & 11 \\
\hline Alcance funcional & 4 & 15 \\
\hline Provas estacionarias & 16 & 11 \\
\hline Transferências & 11 & \\
\hline
\end{tabular}

Participante 6

\begin{tabular}{|l|c|c|}
\hline Grupo de tarefas de Berg & Pontuação pré intervenção & Pontuação pós intervenção \\
\hline Berg (pontuação total) & 52 & 54 \\
\hline Base de sustentação & 12 & 12 \\
\hline Componentes rotacionais & 12 & 12 \\
\hline Alcance funcional & 4 & 4 \\
\hline Provas estacionarias & 15 & 12 \\
\hline Transferências & 11 & \\
\hline
\end{tabular}




\begin{tabular}{|c|c|c|}
\hline हal & $\begin{array}{c}\text { Universidade de São Paulo } \\
\text { FACULdAdE DE MEDICINA DE RIBEIRÃo PRETo } \\
\text { Departamento de Neurociências e Ciências do } \\
\text { Comportamento } \\
\text { Divisão de TERAPIA OCUPACIONAL }\end{array}$ & $\mathbf{N}^{C}$ \\
\hline
\end{tabular}

TERMO DE CONSENTIMENTO LIVRE E ESCLARECIDO

\author{
( $1^{\text {a }}$ fase do estudo)
}

Título da Pesquisa: INFLUÊNCIA DA PRATICA VIRTUAL DE YOGA SOBRE O CONTROLE POSTURAL DE MULHERES IDOSAS UTILIZANDO O NINTENDO WII

Pesquisadora responsável: Prof $^{a}$ Dr $^{\mathrm{a}}$ Carla da Silva Santana, docente do Curso de Terapia

Ocupacional da FMRP-USP

Pesquisador envolvido: Frederico Augusto Costa e Lima Soares.

\title{
ESCLARECIMENTOS AO SUJEITO DA PESQUISA
}

Gostaria de convidá-lo (a) a participar desta pesquisa chamada "Influência da pratica de Yoga sobre o controle postural estático do idoso ativo em ambiente de realidade virtual utilizando o Nintendo Wii” sob a orientação da Prof ${ }^{a}$ Dr $^{\mathrm{a}}$ Carla da Silva Santana. Meu nome é Frederico Augusto Costa e Lima Soares, sou estudante de Mestrado do Programa de PósGraduação Interunidades Bioengenharia da Escola de Engenharia de São Carlos (EESC) e da Faculdade de Medicina de Ribeirão Preto (FMRP) da Universidade de São Paulo (USP).

Esse estudo tem por objetivo verificar os efeitos da prática virtual de Yoga sobre o controle postural funcional do idoso saudável usando o video game Nintendo Wii Fit. Vai ser observado se o Sr(a) melhora o equilíbrio quando usa o jogo Yoga do vídeo game Nintendo Wii.

Para participar desse estudo o $\operatorname{Sr}(a)$ não precisará de nenhum conhecimento anterior nem de vídeo game, nem de Yoga, não precisa ter pratica com atividade física. A forma de pegar informações para este estudo é através de um questionamento onde o $\operatorname{Sr}(a)$ deverá relatar alguns dados pessoais como nome, idade, escolaridade, atividades diárias, passatempos, renda familiar, dificuldades físicas, uso de medicação, uso de aparelhos que ajudem na visão ou audição, se o $\operatorname{Sr}(a)$ sente tonturas; entre outros. Serão realizados também dois questionários escritos que fazem perguntas sobre se o $\operatorname{Sr}(\mathrm{a})$ sente tonturas ou teve quedas recentemente, assim como questionamentos de sua satisfação com a vida e atividades cotidianas (este teste avalia se o Sr(a) possui tendências depressivas). O Sr(a) fará ainda alguns teste de avaliação do equilíbrio que consiste em levantar, andar por três metros em uma sala e sentar-se numa cadeira, levantar e sentar, apanhar objetos no chão, olhar por cima dos ombros, colocar os pés sobre um degrau simulando uma subida de escada, alcançar o mais distante possível a frente sem mover os pés, permanecer em pé com os olhos fechados por 30 segundos e permanecer em uma só perna por 10 segundos.

Passando por essa primeira bateria de exames o Sr(a) será convidado (a) a comparecer em uma segunda fase para realizar um exame mais detalhado de seu equilíbrio, usando para isso uma plataforma computadorizada (a plataforma é um bloco de madeira de cerca de $15 \mathrm{~cm}$ 
de altura com sensores por baixo) especialmente desenvolvida para essa finalidade, onde o Sr(a) terá de subir e realizar 16 diferentes posições para que fiquem gravadas no computador Estas avaliações terão duração de 30 minutos, e serão realizados no Centro Reabilitação (CIR) do Hospital Santa Tereza em Ribeirão Preto - SP.

A segunda fase descrita acima será realizada após 8 semanas para serem comparadas com a primeira avaliação.

Para isso você deve estar ciente de que:

1. Sua participação é voluntária e sua recusa não implicará em prejuízos a suas atividades habituais e o $\operatorname{Sr}\left({ }^{a}\right)$ poderá desistir a qualquer momento;

2. As informações desta pesquisa poderão ser utilizadas para fins de ensino para os estudantes da área da saúde e também e poderão ser apresentadas em eventos ou trabalhos científicos, porém o $\operatorname{Sr}\left({ }^{\mathrm{a}}\right)$ não será identificado por seu nome mantendo seus dados pessoais em total sigilo;

3. Caso o $\mathrm{Sr}\left({ }^{\mathrm{a}}\right)$ aceite participar, será realizada uma entrevista seguida de uma avaliação onde colheremos informações gerais, cujo procedimento é simples, rápido (em torno de 30 minutos) e dispensa qualquer conhecimento especial.

4. O local da entrevista será escolhido de forma que o $\operatorname{Sr}\left({ }^{\mathrm{a}}\right)$ não seja exposto e tenha privacidade para responder as perguntas.

5. Não existe nenhum risco previsto ou eventual à sua saúde em participar. $\mathrm{O} \operatorname{Sr}\left({ }^{\mathrm{a}}\right)$ poderá sentir-se desconfortável por ficar sobre a plataforma e também na sala escura, porem haverá profissionais ao seu lado cuidando para que não caia e se sinta seguro (a);

6. $\mathrm{O} \mathrm{Sr}\left({ }^{\mathrm{a}}\right)$ é livre para interromper, a qualquer momento, a sua participação neste estudo e também poderá obter qualquer informação quando desejar.

7. Não há nenhuma forma de pagamento prevista para a sua participação. $\mathrm{O} \operatorname{Sr}\left({ }^{(a)}\right)$ não terá nenhum gasto com este estudo também não receberá nenhum valor em dinheiro. $\mathrm{O} \operatorname{Sr}\left({ }^{\mathrm{a}}\right)$ terá que dispor de cerca de uma hora e meia do seu tempo.

8. $\mathrm{O} \mathrm{Sr}\left({ }^{a}\right)$ não terá nenhum benefício direto com sua participação, porém terá seu equilíbrio avaliado e caso seja identificado algum problema o $\operatorname{Sr}\left({ }^{a}\right)$ será encaminhado para tratamento adequado.

Tendo recebido as informações sobre o projeto de pesquisa "Influência da pratica de Yoga sobre o controle postural estático do idoso ativo em ambiente de realidade virtual utilizando o Nintendo Wii" sob a responsabilidade da $\operatorname{Prof}^{\mathrm{a}} \operatorname{Dr}^{\mathrm{a}}$ Carla da Silva Santana, eu, RG $\mathrm{n}^{\circ}$ _ aceito

participar deste estudo, ciente de que minha participação é voluntária e estou livre para, em qualquer momento, interromper a colaboração com a pesquisa, sem nenhuma espécie de prejuízo.

Declaro que, após convenientemente esclarecido pelo pesquisador e ter entendido o que me foi explicado, consinto em participar do presente estudo.

Recebi uma cópia deste termo e tive a possibilidade de lê-lo, com o qual concordo.

Ribeirão Preto, de de 
$\overline{\text { Assinatura do pesquisador responsável }}$

Assinatura do sujeito da pesquisa 


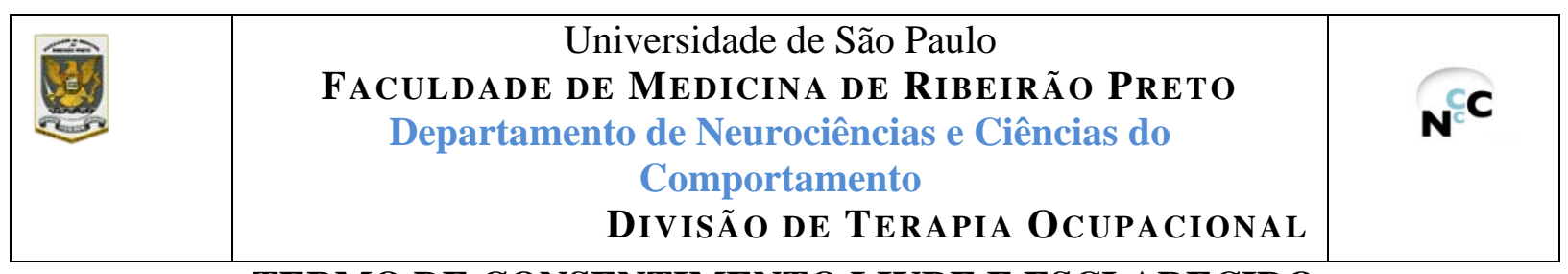

TERMO DE CONSENTIMENTO LIVRE E ESCLARECIDO ( $2^{\text {a }}$ fase do estudo)

Título da Pesquisa: INFLUÊNCIA DA PRATICA VIRTUAL DE YOGA SOBRE O CONTROLE POSTURAL DE MULHERES IDOSAS UTILIZANDO O NINTENDO WII

Pesquisadora responsável: $\operatorname{Prof}^{\mathrm{a}} \mathrm{Dr}^{\mathrm{a}}$ Carla da Silva Santana, docente do Curso de Terapia Ocupacional da FMRP-USP

Pesquisador envolvido: Frederico Augusto Costa e Lima Soares.

\section{ESCLARECIMENTOS AO SUJEITO DA PESQUISA}

Gostaria de convidá-lo (a) a participar deste trabalho. Estou desenvolvendo um projeto de pesquisa intitulada "Influência da pratica de Yoga sobre o controle postural estático do idoso ativo em ambiente de realidade virtual utilizando o Nintendo Wii” sob a orientação da Prof $^{a}$ Dr $^{\mathrm{a}}$ Carla da Silva Santana. Meu nome é Frederico Augusto Costa e Lima Soares, sou estudante de Mestrado do Programa de Pós-Graduação Interunidades Bioengenharia da Escola de Engenharia de São Carlos (EESC) e da Faculdade de Medicina de Ribeirão Preto (FMRP) da Universidade de São Paulo (USP).

Esse estudo tem por objetivo verificar os efeitos da prática de Yoga sobre o controle postural funcional do idoso saudável utilizando o video game Nintendo Wii Fit. (Vai ser observado se haverá melhora do equilíbrio quando se usa o jogo Yoga do vídeo game Nintendo Wii).

Pretendo conhecer as formas que o $\operatorname{Sr}($ a) utiliza para o controle do equilíbrio postural durante um jogo de vídeo game que simula posições de Yoga sobre uma plataforma baixa (cerca de $5 \mathrm{~cm}$ de altura), antiderrapante .

Ao participar desse estudo $\operatorname{Sr}(a)$ poderá ajudar no desenvolvimento de aparelhos voltados tanto para o lazer quanto para auxilio no tratamento de problemas de saúde.

A forma de coletar informações para este estudo é através de uma avaliação do equilíbrio sobre uma plataforma de cerca de $20 \mathrm{~cm}$ de altura onde o $\operatorname{Sr}(\mathrm{a})$ fará as seguintes posições: O Sr(a) ficará com os pés unidos por 30 segundos, com um pé a frente do outro por 30 segundos, e com um só pé por 30 segundos (com os olhos abertos e fechados, com piso firme e com espuma).

Será ainda realizado outro teste em que o Sr(a) fará diversos movimentos como: permanecer sobre um dos pés, mudar de uma cadeira para outra, levantar e sentar, ficar em pé com os olhos fechados, ficar em pé com os pés juntos, alcançar um objeto a frente sem movimentar os pés, pegar objetos no chão, olhar por cima do ombro, colocar os pés alternados sobre um degrau, ficar com um pé a frente do outro. Esses testes serão realizados antes e após as 8 semanas de treinamento com o jogo.

Os exercícios de Yoga são posições como encostar as mãos nos pés, inclinar o corpo para as laterais, manter-se em um só pé, agachar, ficar na ponta dos pés, agachar e ficar na ponta dos pés, ficar em pé com os pés afastados com os braços abertos, entre outra. Tudo realizado sobre a plataforma do jogo.

As avaliações e o treinamento com o vídeo game serão feitos com orientação de profissionais que ficarão o tempo todo responsáveis pela sua segurança. Todos os exercícios são de fácil entendimento e será seguido por dicas mostradas na tela do jogo, caso o $\operatorname{Sr}(a)$ tenha dúvidas poderemos explicar. No total os exercícios de Yoga terão duração de cerca de 
30 minutos, 3 vezes por semana durante 8 semanas seguidas, e serão realizadas em uma sala preparada no Espaço de Cultura e Extensão Universitária (ECEU/USP - centro) em Ribeirão Preto - SP.

Para isso você deve estar ciente de que:

1. Sua participação é voluntária e sua recusa não implicará em prejuízos a suas atividades habituais e o $\operatorname{Sr}\left({ }^{a}\right)$ poderá desistir a qualquer momento;

2. As informações desta pesquisa poderão ser utilizadas para fins de ensino para os estudantes da área da saúde e também e poderão ser apresentadas em eventos ou trabalhos científicos, porém o $\operatorname{Sr}\left({ }^{a}\right)$ não será identificado por seu nome mantendo seus dados pessoais em total sigilo;

3. Caso o $\mathrm{Sr}\left({ }^{\mathrm{a}}\right)$ aceite participar, será realizada uma entrevista, avaliação e treinamento de Yoga com o vídeo game. Estas avaliações e exercícios serão marcados em um horário que seja mais adequado para o senhor(a) e dispensa qualquer conhecimento especial.

4. O local da entrevista será escolhido de forma que o $\operatorname{Sr}\left({ }^{a}\right)$ não seja exposto e tenha privacidade para responder as perguntas.

5. Não existe nenhum risco previsto ou eventual à sua saúde em participar. $\mathrm{O} \operatorname{Sr}\left({ }^{(a)}\right.$ poderá sentir-se desconfortável por ficar sobre a plataforma, porem haverá profissionais ao seu lado cuidando para que não caia e se sinta seguro (a);

6. $\mathrm{O} \mathrm{Sr}\left({ }^{\mathrm{a}}\right)$ é livre para interromper, a qualquer momento, a sua participação neste estudo e também poderá obter qualquer informação quando desejar.

7. Não há nenhuma forma de pagamento prevista para a sua participação. $\mathrm{O} \operatorname{Sr}\left({ }^{\mathrm{a}}\right)$ não terá nenhum gasto com este estudo também não receberá nenhum valor em dinheiro. $\mathrm{O} \operatorname{Sr}\left({ }^{\mathrm{a}}\right)$ terá que dispor de cerca de uma hora e meia do seu tempo (entre transporte e participação).

8. O benefício previsto por sua participação é a possibilidade de ter seu equilíbrio avaliado e treinar sua capacidade física. Após terminada a pesquisa nos o orientaremos a locais onde o $\mathrm{Sr}$ / Sra poderá realizar atividades físicas.

Tendo recebido as informações sobre o projeto de pesquisa "Influência da pratica de Yoga sobre o controle postural estático do idoso ativo em ambiente de realidade virtual utilizando o Nintendo Wii” sob a responsabilidade da $\operatorname{Prof}^{\mathrm{a}} \operatorname{Dr}^{\mathrm{a}}$ Carla da Silva Santana, eu, RG $\mathrm{n}^{\circ} \longrightarrow$ aceito

participar deste estudo, ciente de que minha participação é voluntária e estou livre para, em qualquer momento, interromper a colaboração com a pesquisa, sem nenhuma espécie de prejuízo.

Declaro que, após convenientemente esclarecido pelo pesquisador e ter entendido o que me foi explicado, consinto em participar do presente estudo.

Recebi uma cópia deste termo e tive a possibilidade de lê-lo, com o qual concordo.

Ribeirão Preto, de de 


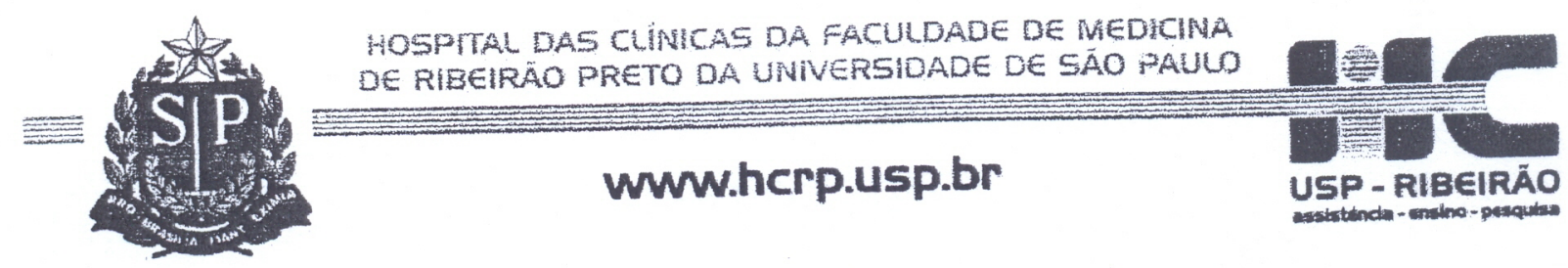

Ribeirão Preto, 20 de outubro de 2010

Ofício $\mathrm{n}^{\circ} 3574 / 2010$

$\mathrm{CEP} / \mathrm{MGV}$

Prezados Senhores,

O trabalho intitulado "EFEITOS DA PRÁTICA DE YOGA SOBRE O CONTROLE POSTURAL FUNCIONAL DO IDOSO SAUDÁVEL UTILIZANDO O NINTENDO WII", foi analisado "AD REFERENDUM ${ }^{\text {}}$ pelo Comitê de Ética em Pesquisa e enquadrado na categoria: APROVADO, bem como o Termo de Consentimento Livre e Esclarecido, de acordo com o Processo HCRP n 9514/2010.

Este Comitê segue integralmente a Conferência Internacional de Harmonização de Boas Práticas Clínicas (IGH-GCP), bem como a Resolução no 196/96 CNS/MS.

Lembramos que devem ser apresentados a este CEP, 0

Relatório Parcial e o Relatório Final da pesquisa.

Atenciosamente.

DR MARCIA GULMARÁS VILANOVA

Vice-Coordenadora do Comitê de titica em

Pesquisa do HCRP e da FMRP-USP

Ilustríssimos Senhores

FREDERICO AUGUSTO COSTA E LIMA SOARES

PROF" DR CARLA DA SLVA SAMTANA (Orieptadora)

Depto. de Neurociências e Ciências do Comportamento - Terapia Ocupacional

Comité de Ética em Pesquisa HCRP e FMRP-USP - Campus Universitánio FWA - 0000 2733; IRB - 00002186 R Registro SISNEP/CONEP $n^{\circ} 4$ Fone (16) 3602-2228 - E-mail : cep@hcrp.usp.br Monte Alegre 14048-900 Ribeirăo Preto SP 